\title{
RGD collagen for engineering a contractile tissue and cell therapy after myocardial infarct
}

Olivier Schussler ${ }^{1}$ Pierre E. Falcoz ${ }^{2}$, Juan C. Chachques ${ }^{3}$, Marco Alifano ${ }^{1,4}$, Yves Lecarpentier ${ }^{5}$

${ }^{1}$ Thoracic Surgery Department, Cochin Hospital, APHP Centre, University of Paris, France

${ }^{2}$ Department of Thoracic Surgery, University Hospital Strasbourg, Strasbourg, France

${ }^{3}$ Department of Cardiac Surgery Pompidou Hospital, Laboratory of Biosurgical Research, Carpentier Foundation, University Paris Descartes, 75015 Paris, France

${ }^{4}$ INSERM U1138 Team «Cancer, Immune Control, and Escape», Cordeliers Research Center, University of Paris, France

${ }^{5}$ Centre de Recherche Clinique, Grand Hôpital de l'Est Francilien, Meaux, France

${ }^{\circ}$ Correspondance : olivier.schussler@gmail.com 


\begin{abstract}
:
Currently, the clinical impact of cell therapy after a myocardial infarction (MI) is limited by low cell engraftment due to significant cell death, including apoptosis, in an infarcted, inflammatory, poor angiogenic environment, low cell retention and secondary migration. Cells interact with their environment through integrin mechanoreceptors that control their survival/apoptosis/differentiation/migration/proliferation. Optimizing these interactions may be a way of improving outcomes.

The association of free cells with a 3D-scaffold may be a way to target their integrins. Collagen is the most abundant structural component of the extracellular matrix (ECM) and the best contractility levels are achieved with cellular preparations containing collagen, fibrin, or Matrigel (i.e. tumor extract). In the interactions between cells and ECM, 3 main proteins are recognised: collagen, laminin and RGD (Arg-Gly-Asp) peptide. The RGD plays a key role in heart development, after MI, and on cardiac cells. Cardiomyocytes secrete their own laminin on collagen. The collagen has a non-functional cryptic RGD and is thus suboptimal for interactions with associated cells.

The use of a collagen functionalized with RGD may help to improve collagen biofunctionality. It may help in the delivery of paracrine cells, whether or not they are contractile, and in assisting tissue engineering a safe contractile tissue.
\end{abstract}

Keys words: integrins -RGD- adhesion molecules-contractility-collagen-tissue engineeringmyocardial infarct 


\section{Introduction}

Despite a remarkable decline in initial cardiovascular deaths, acute coronary occlusion is the major cause of heart failure, with a mortality rate of $50 \%$ at 5 years [1]. Acute coronary occlusion leads to ischemic cardiomyocyte death and subsequent alteration of contractility due to the impossibility of replacing the loss of cardiomyocytes, at least in a sufficient quantity, given that less than $1 \%$ of cardiomyocytes are renewed each year [2]. In addition, myocardial infarct (MI) is associated with a profound alteration of the physical and biological properties of the cardiac extracellular matrix (ECM). MI is associated with the acute degradation of the ECM, which is mainly composed of collagen, its main structural component [3, 4]. In rat, 12 hours after MI, already $75 \%$ of collagen type I and type III has been lost. After 2 days, the collagen progressively re-increases with an overcompensation at 5 days, with collagen type I but not type III [5]. In rat, after MI, early left ventricle unloading has been shown to preserve collagen content. However, the original orientation of collagen fibers is still lost. In humans, unloading has been shown to not affect the laminin content of cardiac ECM, but there is a decrease in the very bioactive collagen type IV and an alteration of both the number and quality of the contacts between cardiomyocytes and ECM [6].

Preclinical and clinical studies have shown that cell therapy attenuates myocardial damage and the progression to heart failure, although the detailed mechanisms involved have not been determined [7-9]. After MI, for optimal efficiency, cells should be transplanted as soon as possible, probably within the first $72 \mathrm{~h}$, and possibly in the first few hours [10]. Early stem cell engraftment has been shown to predict late functional cardiac recovery [11]. Today, the clinical impact of cell therapy is limited by low cell engraftment [9]. With respect to free cell injections, a limit has been observed in the peri-infarct area, with low cell retention, secondary cell migration, and cell apoptosis in ischemic and damaged areas. Cardiac cells, like most somatic cells, interact with the classical natural ECM through integrin mechanoreceptors that control many cellular signals for cell survival, apoptosis, differentiation, migration and proliferation. Integrins recognize an oligopeptide on the ECM proteins. Optimization of this interaction may be a way of improving the results of cellular therapy. 3D cultures have been shown to enhance cell ECM interactions through integrins and cell-cell interactions. In most preparations in $3 \mathrm{D}$ cultures, integrin expressions are increased. Nowadays the most promising cell types for cell therapy are multipotent human mesenchymal stem cells and resident cardiac stem cell preparations, such as "Cardiospheres" and cardiomyocytes derived from iPS-CM or ES-CM [12]. The functionality of all these preparations has been shown to be related to their 
paracrine potential and not their effective contractility [12]. Associating the cell with 3D scaffolds is the most promising way to improve cellular transplantation, especially if the cellcontaining preparations are applied to the epicardium instead of using intramyocardial delivery [13-17]. The association of cells in a patch that is applied to the myocardium and not to the injured area may also be a way to control the physical properties of the cell environment, namely stiffness, biological composition, and interactions with integrins over a prolonged period. Currently, the most commonly used methods for cell delivery in clinical trials are direct intramyocardial injections or intracoronary infusions. In both cases, the proportion of cells retained is very low and is believed to limit treatment efficacy. Animal studies have shown that engraftment is substantially higher if the cells are transferred as a contractile tissue rather than via free cell injections or infusions [9]. Thus in vitro engineering of a contractile heart tissue, designed to morphologically and functionally resemble the native myocardium before transfer, could enhance cell engraftment, providing a distinct advantage over direct intramyocardial cell injection $[9,12,16,18]$.

The crucial role of integrins on therapeutic cardiac cells has been well demonstrated. It has been shown that the presence of injectable collagen type I with human angiogenic progenitor cells increases their functionality in an ischemic model, by enhancing interaction with integrins $\alpha 5$ for fibronectin and $\alpha 2 \beta 1$ for collagen[19]. The attachment, retention and therapeutic benefits of "human cardiospheres" in a SCID mouse model of infarct have been shown to be dependent on pretransplant $\beta 3$ expression (i.e. RGD) on those cells that determined attachment to fibronectin in the MI area [20]. Integrins recognizing the RGD motif have been shown to play a key role during cardiac development, hypertrophy and after MI. After MI, most proteins, especially ECM proteins that contain the RGD motif, promote tissue regeneration and angiogenesis, and the RGD portion of these proteins is involved in providing the main beneficial effect. In humans, after MI, the RGD expression is limited to the peri-infarct areas and labeled angiogenic endothelial progenitors and fibroblasts and myofibroblasts. An early increase in RGD capture is associated with an improved outcome in terms of MI size and contractility recovery [21-23]. After infarction, the cells involved in the regenerative process are in the epicardial layer [24] and may thus be better treated with an epicardial therapy. Interaction of regenerative cells with the local RGD motif of fibronectin has been shown to be essential for their functionality and regenerative capability [25].

Local non-cellularized patches of collagen with a therapeutic agent and epicardial application has been shown to have some functionality. The application of compressed collagen 
with FSLT1 (follistatin -like1) to the infarct area 10 days after MI has been shown to improve cardiac function and survival in mouse and swine models of myocardial infarction, but the intramyocardial administration of cells secreting this factor has not proved efficient [26]. Moreover, a collagen patch delivering the matricillin protein periostin that contains the RGD, when applied epicardially, has been shown to improve outcomes after MI [27]. We have been able to demonstrate, first in mice [28] and then more recently in humans requiring a bypass after MI [29, 30], how, in addition to intramyocardial free cell injection, the application of cells in a solid collagen patch is considerably more effective.

Up to now, the best contractility results in vitro have been reported with natural material containing only collagen (collagen, gelatin, decellularized tissue) or fibrin. In solid collagen scaffolds, it is necessary to use for cell seeding to use a gel obtained from mouse tumor cells composed of extracts of basement membranes (i.e. Matrigel TM). However, the presence of this gel alters nutriment diffusion and thus a bioreactor is necessary for cell survival [31-33]. Cardiac cells (i.e. cardiomyocytes [34, 35], fibroblasts, myofibroblasts, endothelial cells, mesenchymal stem cells, stem cells) interact with the ECM through a specific set of integrin mechanoreceptors. There are 3 main types of interaction with proteins: collagen, laminin and "RGD", an oligo-peptide that is present on fibronectin or vitronectin proteins. On 2D and 3D cultures, it has been shown that an early secretion of laminin by cardiomyocytes on collagen type I, after a few hours, induces and controls the organization of cardiac sarcomeres [36]. The RGD is present on the collagen but in a cryptic non-functional form [37]. By using neonatal rat cardiomyocytes in a solid DHT scaffold, we demonstrated how its functionality could be improved with RGD [38]. It was possible to engineer a very efficient contractile tissue without the need for Matrigel ${ }^{\mathrm{TM}}$ and the perfusion of bioreactors [39]. The gelatin is obtained by heat denaturation of collagen and contains a functional RGD motif. It has a low porosity and very poor mechanical properties, so that some adhesion molecules, such as collagen receptors for integrins, are lost during the transformation. We also reported how the collagen-RGD scaffolds increase the cardiogenic potential of clinical "Human Cardiospheres" in comparison with gelatin-based solid foams of the same stiffness or the classical cultures such as " $3 \mathrm{D}$ cell clusters" [40]. Optimization of the gel by reticulation may be a way of improving its physical parameters (stiffness, pore size, orientation and control of degradation) and of facilitating the transfer of the preparation. Chemical reticulation has been shown to alter the functionality of adhesion molecules on collagen and gelatin [41-43]. Physical reticulation by DHT is a mild 
reticulation but offers the same reticulation capability, while preserving scaffold biofunctionality.

We have recently demonstrated in vitro how the presence of RGD-functionalized collagen promotes the differentiation of human mesenchymal stem cells (MSC) towards contractile myofibroblasts and improves contractility by enhancing actin-myosin crossbridge mechanical properties [44-46]. In a 3D construct of collagen, we also demonstrated the preservation of MSC important paracrine activity, even after differentiation into contractile myofibroblasts. The paracrine activity in 3D scaffolds is shown to be superior to that in classical 2D cultures [44]. This observation has also been confirmed by another research group, but in their experiment the MSCs in the collagen scaffold were still associated with Matrigel ${ }^{\mathrm{TM}}$ [47].

We anticipate that the functionalization of the collagen polymers used in making the 3D collagen scaffolds that will be used for epicardial delivery or intramyocardial therapeutic cell delivery may well be improved by the functionalization with the RGD peptide that is present but not functional on the collagen $[17,38]$. The RGD collagen scaffolds may be used for therapeutic cell delivery. Optimizing the recognition of key integrins may be a way of controlling cell retention and differentiation as well as enhancing cell survival in hypoxic and damaged myocardium and, therefore, of improving the results of cell therapy after MI. More generally, functionalization of the collagen polymers with the RGD may also be a way of improving contractility in collagen-based constructs.

\section{Integrins: General and RGD For recent reviews [48-55]}

\subsection{Integrin structure, physical interaction with cytoplasmic and nuclear cytoskeleton, intercellular cadherin and biological functions}

Integrins are composed of two different sub-units, $\alpha$ and $\beta$, which are assembled into 24 different combinations of heterodimers with individual specificities regarding the ECM [56]. Integrins are the main class of cell surface receptors that recognize the oligopeptides present on proteins of the ECM. Cells have developed cell surface receptors and mechanosensors (.e. integrins), that bridge ECMs and the cytoskeleton following integrin activation. Integrins relay signals between the extracellular environment and intracellular pathways, a communication that occurs in both directions [53]. As cell adhesion molecules, integrins function as mechanical connectors [57-59]. Such a dual role makes integrins prime candidates for force-sensing molecules in mechanotransduction. By connecting the cell cytoskeleton with the ECM, 
integrins are continuously submitted to forces transmitted between cells and the ECM. Mechanical stimulation is associated with changes in integrin properties such as ligand binding kinetics, conformation, activation, clustering and diffusion [53]. Integrins at the membrane surface can couple to other molecules such as growth factors, proteoglycans and tetraspans that influence their assembly and function. Besides integrins, the dystroglycan complex is another mechanical link between the ECM and the cardiomyocyte cytoskeleton. As mechanoreceptors, the integrins are able to evaluate many characteristics of the EMC such as stiffness and viscoelasticity, and transduce information from the cytoskeleton to the nucleus and gap junctions between cells [51, 52].

Catch bonds correspond to the ability of integrin-ligand bonds to be strengthened by intra- or extra-cellular forces. This provides a physical mechanism for force sensing if different bond lifetimes correspond to different activation states that transduce distinct signals [60]. Intracytoplasmic application of an acto-myosin driving force to intracellular integrin $\beta$ tails will switch the relaxed state to a new tensioned state with increased bond strength. The acto-myosin plays also a key role in force re-enforcement and in sensing and adhesion-complex maturation and clustering by physical interaction through the control and physical association of vinculin with talin, the master of integrin adhesion [61]. This makes a physical link between the ECM, integrin, talin, actin and skeleton (Fig 1). Vinculin activity depends on mechanical activation and is also a key regulator at cell-cell contacts at the level of cadherins [62].

Integrins, through the cell cytoskeleton, are also connected to the intercellular calciumdependent gap junction protein, cadherin. Classically, cadherins form homotypic bonds with other cadherins on neighboring cells and mechanically link the cytoskeletal elements. However, it has recently been shown that cadherins can also have their own signaling with downstream effectors, including $\beta$-catenin. The physical stimulation of integrins has been shown to reinforce intercellular gap junctions with increased $\mathrm{N}$-cadherin expression [63]. In cardiomyocytes, $\mathrm{N}$ cadherin has a role in the transmission of forces and electrical signals between cells [64][64]. Cadherins mediate mechanically induced signaling between cells through adherens junctions, which link cadherins to the cytoskeleton. Cadherin senses intercellular forces. Research has also shown a force, dependent on interaction between vinculin and $\alpha$-catenin, results in strengthening the integrin adhesion site and increasing contractility [65,66]. Integrins and cadherins probably share a common mechanosensive mechanism in which vinculin induces the stabilization of adhesion complexes of integrins or the stabilization of adherens junctions between cells. At the same time, there is a feedback from intercellular coupling to integrins. 
Cardiomyocytes from mice $\mathrm{KO}$ for $\mathrm{N}$-cadherin have shorter sarcomeres and the $\beta 1$ integrin level is surprisingly increased, which suggests a possible compensatory phenotype. The cadherin intracellular domain is associated with $\beta$-catenin. $\beta$-catenin will bind $\alpha$-catenin to the cellular cytoskeleton $\alpha$ actin. $\alpha$-Catenin also recruits vinculin to the cadherin complex, which is crucial for integrin receptor activation. $\alpha$-Catenin has been shown to regulate cytoskeletal mechanotransduction, which in turn can regulate YAP-mediated cell proliferation.

\subsection{Oligopeptides (including the "RGD" oligopeptides) recognized by integrins on the ECM proteins}

Apart from the interaction of leucocytes, there are 3 main types of interaction between cells and the ECM through integrins: with collagen, with laminin, and "RGD" type interactions (for fibronectin and vitronectin). Integrins recognize oligopeptides present on the proteins of the ECM or basal membrane. This limited interaction with oligopeptides is in most cases sufficient to reproduce full protein functionality [67].

For recognition of collagen or laminin, the $\beta 1$ chain is associated: with $\alpha 1, \alpha 2, \alpha 10$, $\alpha 11$ (i.e. $\alpha 1 \beta 1, \alpha 2 \beta 1, \alpha 10 \beta 1, \alpha 11 \beta 1)$ for the collagen main oligopeptide "GFOGER", and with $\alpha 3, \alpha 6, \alpha 7$ (i.e. $\alpha 3 \beta 1, \alpha 6 \beta 1, \alpha 7 \beta 1$ ) for laminin. $\alpha 6 \beta 4$ can also recognize laminin $[68,69]$. Beside "GFOGER" oligopeptide, there are other recognition sequences in collagen such as "KGD" in the ectodomain of collagen XVII, which is recognized by $\alpha 5 \beta 1$ and $\alpha v \beta 1$ integrins. Several bioactive fragments, resulting from the proteolytic cleavage of collagens by matricryptins, reveal cryptic sites that are ligands for $\alpha v \beta 3$, $\alpha v \beta 5, \alpha 3 \beta 1$, and $\alpha 5 \beta 1$ integrins. The collagen also contains the important RGD motif but in a cryptic form that is non-functional if the collagen is not denaturated by heating (i.e. as for gelatin [70]) or enzymatically digested [71]. Denaturation of collagen by heating (such as for gelatin) is also associated with the loss important structural properties and also the loss of the main collagen receptor "GFOGER" [70].

The RGD motif is present in different forms: linear, such as in the fibronectin protein, or cyclic, such as in the vitronectin protein. The RGD motif can be recognized by $\alpha 5 \beta 1, \alpha 8 \beta 1$, $\alpha_{v} \beta 3, \alpha_{v} \beta 5, \alpha_{v} \beta 6, \alpha_{v} \beta 8$ [52]. The recognition of RGD by $\alpha v \beta 3, \alpha_{v} \beta 5 \alpha_{v} \beta 6, \alpha_{v} \beta 8, \alpha 5 \beta 1$ depends on their cyclic or linear form, but also on the flanking region of the RGD peptide [72]. For the oligopeptide "RGD", the main interaction involves a recognition site on the extracellular domain of the $\beta$ chain but also the flanking region of the peptide that will interact with the extracellular $\alpha$ chain that creates the binding site and determines the integrin specificity. The 
cyclic RGD is more likely to be recognized by the $\alpha v$ type of integrins (e.g. $\alpha v \beta 3, \alpha v \beta 5 \alpha v \beta 6$, $\alpha v \beta 8$ ) while the linear RGD form is recognized by $\alpha v b 3, \alpha v \beta 5$ integrins and $\alpha 5 \beta 1$, with different affinity.

The linear G-RGD-S peptide we have used in most experiments corresponds to the complete linear motif of the RGD peptide that is present in fibronectin. This linear peptide has a preferential affinity for $\alpha 5 \beta 1$ and $\alpha v \beta 3$, but not for other $\alpha v$ integrins such as $\alpha v \beta 5, \alpha v \beta 6$, $\alpha v \beta 8$.

\subsection{The different integrin activation states}

Several types of integrin heterodimers are expressed on the cell at the same time. The expression depends on: cell types, maturation and activation state, environment (ECM, cell-cell contact, cell-matrix, physical parameters (stiffness/viscoelasticity/curvature), 2D or 3D environment, normal versus pathological heart (failing post MI).

For each specific integrin, there are at least 3 types of conformation corresponding to different activation states: "bent closed" (BC), "extended closed" (EC) and "extended open" (EO) [55] (Figure 1). With regard to affinities for the RGD peptide, that of the "extended open" (EO) integrin compared to that of the "extended closed" (EC) integrin is 4000 to 6000 -fold greater [52]. All the states exist at the same time on the cell surfaces, but the inactive form (BC) is predominant. Less than $1 \%$ only are in a highly active open form, most integrins being in an inactive state (closed integrin). Considering integrin $\alpha 5 \beta 1$, in the absence of ligands, the integrin is in a bent closed (BC) form [52]. On the plasma membrane, inside-out mechanisms, in conjunction with extracellular $\mathrm{mg} 2+$ and force from the ECM, allow integrin unbending and separation of the integrin $\alpha$ and $\beta$ legs (opening), resulting in activation and increased affinity for ligand binding. Inside-out signaling regulates displacement of intracellular integrin inhibitors and allows talin binding to integrin $\beta$ tail, thereby tightly controlling integrin affinity. The contractility on talin by $\alpha$-actin/myosin and vinculin will reinforce the deformation of $\beta$ tail and promote full integrin receptor activation and maintenance of the high affinity extended open state of the integrin. Talin is the protein that binds directly to the $\beta$ chain and provokes integrin extracellular domain mechanical secondary conformation changed, thus playing a key role in initial integrin activation (Figure 1). Kindlin also plays an important role by allowing integrin activation by binding the integrin $\beta$ chain and by recruiting key focal adhesion proteins such as paxillin. 


\subsection{Integrin initial activation, FAK formation, clustering and focal adhesion complex maturation}

While protein-protein interactions typically have a shorter lifetime under load, the bond between fibronectin and integrin $\alpha 5 \beta 1$ and $\alpha v \beta 3$ has been found to function as a catch bond, becoming stronger when a force is applied. The cytoplasmic domain of integrin $\beta$ can be bound by $\alpha$-actinin, talin, kindlin, tensin and sharpin. During maturation of the adhesion complex, talin-induced activation is replaced by actin-tensin pulling on the integrin intracellular $\beta$ tail [53].

If the mechanical forces is prolonged and stimulus intense (i.e. high-density ligand, high stiffness), clustering occurs between different integrins (Figure 1). Low ligand density with distance $>200 \mathrm{~nm}$ and low rigidity (around $1.5 \mathrm{kPa}$ ) do not promote clustering and low intracellular forces are developed. Medium ligand density (distance between ligands of below $60 \mathrm{~nm}$ ) and medium ECM rigidity favors force development. High ECM rigidity of around 150 $\mathrm{kPa}$ and high ligand density promote intracellular actin crosslinking and the development of high intracellular force [53,55].

Integrin-mediated adhesions have often been classified according to a maturation sequence: nascent adhesions, focal adhesion, maturation to fibrillary adhesion formation. In these latter complexes, talin is replaced by tensin (Figure 1) [52]. Force adhesion to fibronectin follows 3 steps. High force adhesion mediated by $\alpha 5 \beta 1$ to RGD (distance of around $40 \mathrm{~nm}$ ) if the ligand is anchored to the ECM. The initial focal adhesion complex (FAK) involves the traction of actin-myosin to talin bound to $\beta$ chains and secondarily recruitment of vinculin that will make bounds between actin and talin (Figure 1). There will be an initial clustering of $\alpha 5 \beta 1$, followed by the recruitment of $\alpha v$ integrins [73][82]. $\alpha v \beta 3$ are reinforcing adhesion sites and transduce force into a stiffening signal instead of increasing adhesion strength. The mechanism of clustering is not quite clear and may depend on integrin types, so that it requires at least extracellular binding, talin-head/integrin interactions and talin and kindlin binding to phospholipids in the plasma membrane. Kindlins are cytoplasmic proteins that directly interact with the $\beta$ chain tail and are required for correct assembly of FAK. The actin-myosin contractions at adhesion sites provoke an $\alpha$-actin flow that determines local focal adhesion orientation.

\subsection{Integrin signaling in general and in adhesion complexes upon maturation}


Integrins do not possess their own enzymatic or actin-binding capacity. Therefore, various adaptor proteins are required to allow binding to the cytoplasmic tails of $\alpha$ and $\beta$ subunits in order to mediate integrin activation and subsequent ECM binding to extracellular $\beta$ chain in a so called outside-inside signaling process. There are 3 groups of adaptors: 1 ) those with a structural function (talin, filamin, tensin, vinculin, $\alpha$-actin); 2) those with a scaffolding function that provides binding sites for additional FAK proteins, such as PINCH or paxillin; 3) catalytic adaptors, such as Fak, Src and PP2A, that facilitate the propagation of signals from cellular adhesion sites (for review [34]).

Ligand binding to extracellular domains of integrin can produce a wide range of intracellular signals termed "outside-in signaling" such as integrin link kinase (ILK), focal adhesion kinase (Fak), paxillin, vinculin, talin, kindling and Src. Propagated signals varie and include Akt, JNK, ERK, p38, and NFKB. In contrast to these extracellular events, integrins can also trigger direct or indirect binding to the integrin intracellular cytoplasmic domain, enabling integrin "activation". These processes are known as "inside outside signaling”. Integrins recruit hundreds of proteins in building the so-called adhesome. The different proteins have recently been regrouped into 4 mains categories: 1) Ilk-PINCH-kindlin, 2) FAK-paxillin, 3) Talinvinculin and $\alpha$-actinin-zyxin-VASP.

Five main functions are mediated by integrin adaptors: 1) activation, 2) de-activation, 3) inhibition 4) signaling and 5) mechanosensing.

The integrin regulator adaptor activators are talin and kindlin, both of which bind to the integrin intracytoplasmic $\beta$ chain. Phosphorylation by kinases, namely Fak and Src, increase the turnover of integrins and integrin-mediated adhesion. The talin-vinculin complex is an essential physical link between the integrin $\beta$ chain intracytoplasmic tail and the cytoskeleton. This is essential for FAK assembly. Talin is also essential for integrin activation.

Integrin adaptor de-activators: There are several ways for integrin inactivation to occur: proteolytic degradation of integrin adaptors, phosphorylation of integrins or adapters. Lack of force can also contribute to integrin inactivation. In the nascent focal complex, force is mediated by $\alpha$-actin-myosin on vinculin that is bound to the talin attached to the integrin $\beta$ chain.

When the adhesome matures to a fibrillary adhesion complex, with a high level of integrin crosslinking, the integrins stay in an activated form and integrin clustering is mediated by tensin, which replaces talin and vinculin (Figure 1). Tensin then enables the physical attachment 
between $\alpha$ actin and integrin $\beta$ chains [53][56]. Inhibition of integrins can be performed by ligands that bind to $\alpha$ and $\beta$ chains of integrins in a closed bent conformation such as filamin A.

Signaling adaptors include kinase, such as Fak, and paxillin, which recruits GTPase-activating proteins and thus regulates Rho-GTP ase and the organization of the actin cytoskeleton.

Mechano-adaptors include Src that is phosphorylated upon stretching. Talin is an example of a mechano-adaptor having several cryptic vinculin and hidden actin-binding sites that become accessible when the talin rod domain is put under tension.

An important transducer of stress after integrin activation is the cytoplasmic phosphorylation of YAP/TAZ and then the cytoplasmic transfer of YAP/TAZ through the physical enlargement of nuclear pore complexes into the nucleus and the secondary facilitation of proliferation [51]. Integrin adhesion maturation affects the cell downstream response in different ways. First, it involves the recruitment and activation of signaling proteins such as FAK, paxillin, SRC or ERK. Mature focal adhesion also leads to enhanced actin polymerization and the formation of actin stress fibers, producing two types of effects. Actin polymerization directly affects the release of MKL1 from non-polymerized G-actin or YAP/TAZ. Second, stress fibers mechanically connect the ECM and integrin adhesions to the nucleus via the Linker of Nucleoskeleton and Cytoskeleton (LINC) complex. This leads to an increase in nuclear pore size, thus facilitating TAP/TAZ localization, chromatin remodeling and the exposure of transcription sites.

\subsection{Integrin regulation of membrane expression and recycling}

Integrin protein stability at the membrane is determined in part by its turnover rate. Integrin-dependent cell adhesions are dynamic and undergo constant renewal. This process involves disassembly of the integrin adhesion complexes, endocytosis, recycling back to the membrane, or degradation. Both active and inactive integrin heterodimers are constantly endocytosed from cell surfaces and active integrins continue to signal from endosomes. Endocytosed integrins are recycled back to the plasma membrane or degraded in lysosomes [53].

\subsection{Integrins and substrate stiffness sensing}


Several studies have shown that ECM ligand density and spatial distribution and viscoelasticity can affect cell responses independently of rigidity. Whereas forces are actively transmitted through integrins, rigidity is a passive mechanical parameter that can be directly sensed by cells. To probe rigidity, cells need to actively use their actomyosin cytoskeleton to deform their surrounding ECM through integrin bonds. It has been shown that substrate stiffness sensing mainly involves $\alpha 5 \beta 1$.

In a $2 \mathrm{D}$ system with a polyacrylamide gel coated with collagen, substrate stiffness determines the differentiation with myotube formation. This occurs for a substrate stiffness of between $2.5 \mathrm{kPa}$ and $25 \mathrm{kPa}$, with an optimum value at $12 \mathrm{kPa}$. On substrates with low stiffness, such as $2.5 \mathrm{kPa}$, no myotubes are present initially at 2 weeks, but $5 \%$ are present later after 4 weeks. Substrates with intermediate rigidity induce overexpression of integrins $\beta 1, \alpha 3$ and $\alpha 7$. Myosin IIA and myosin IIB increase with stiffness. With iPS-CM, cardiogenic differentiation and maturation of sarcomeres can be obtained in the same manner in a 2D system on fibronectin or laminin on soft substrates (around $12 \mathrm{kPa}$ ), but not on stiffer substrates.

\subsection{Integrins and viscoelasticity sensing (for review [74,75])}

It was reported in 2D and 3D cultures that stiffness, viscoelasticity, peptide density and presentation are independent parameters determining the capability of MSC differentiation [74]. Activation of $\alpha 5 \beta 1$ promotes integrin clustering and the recruitment of $\alpha \mathrm{v}$ integrins, such as $\alpha v \beta 3$ and $\alpha v \beta 5$, which are necessary for viscoelasticity sensing. Traction by the cells on $\alpha v$ integrins is involved in viscoelasticity sensing. In deforming the surrounding matrix, cells experience a resistive force, the magnitude and time scales of which are defined by the mechanical properties of the matrix, including stiffness and viscoelasticity relaxation. The collagen network determines the major viscoelastic component of human ECM [76]. Reticulation of collagen (biological or chemical/physical) decreases its viscoelasticity. Reconstituted ECM materials, such as collagen type I gel and fibrin gels, are viscoelastic. We have recently characterized the viscoelasticity of the solid DHT collagen scaffold that has been physically crosslinked [45, 46].

With regard to MSCs in 3D substrates, for those substrates with a high stiffness of around $30 \mathrm{kPa}$, the effect of stiffness is far more important than viscoelasticity sensing, but for substrates with low stiffness (i.e. around $1 \mathrm{kPa}$ ), the viscoelasticity with stress relaxation times is more important [74]. The presence of the viscoelastic element G', can greatly influence the 
differentiation capability of MSCs with respect to all the phenotypes [77]. Varying the creep component for a 3D substrate that has the same compliance as the muscle tissue $(13.5 \mathrm{kPa})$ promotes the differentiation of MSCs towards muscular differentiation. Increasing creep enhances MSC differentiation by increasing the expression of endogenous $\beta 1$ and prolongs its membrane expression. Collagen synthesis by cells is also significantly increased by the creep element.

In the presence of cell U2OS or mouse fibroblasts seeded in 3D alginate RGD, with or without viscoelasticity, a viscoelasticity component enhances the spreading and formation of stress fibers, even at a very low compliance level of $1.4 \mathrm{kPa}$. Creep is also associated with increased intercellular $\mathrm{N}$-cadherin expression.

\subsection{Integrins and nanotopography, curvature and ultrastructure sensing}

Nanotopography influences cell response independently of other factors (For review [78]). Cells can perceive variations of a few nanometers on the surface topography and actively respond to the nanotopography. In the 3D matrix, a cell can interact with structures of several micrometers. Structures of up to $30 \mathrm{~nm}$ induce the formation of focal adhesions and stress fibers, which decrease on structures of more than $100 \mathrm{~nm}$. With human h-iPS-cardiomyocytes cultured on 2D substrates, longitudinal grooves of 700-1000 nm promote maturation of the contractile apparatus.

Recently, it has been shown in 3D cultures that the ultra-structural 3D collagen fibrillary network promotes MSC differentiation independently of substrate stiffness [78].

\subsection{Integrin expression in $2 D$ and $3 D$ environments}

In $3 \mathrm{D}$ cultures, cell matrix interactions and cell/cell contacts are more enhanced than in 2D cultures, thereby promoting integrin expression, FAK and integrin signaling [79]. In 3D fibrin gels, as compared with $2 \mathrm{D}$ with human myoblasts, there is an increase in integrin $\alpha 5$ (x10), vinculin (x2), $\alpha$ actin and myosin expressions, with an optimum at $12 \mathrm{kPa}$ for differentiation. However, while integrins and vinculin are restricted to the cell periphery in $2 \mathrm{D}$ cultures, under 3D conditions integrins and vinculin are homogenously distributed over the cell surface [80]. The levels of expression of FAK and actin are similar. However, the organization of $\alpha$ actin differs between 2D and 3D cultures, with actin fibers mainly located at the cell periphery in 2D cultures. In $3 \mathrm{D}$ cultures, $\alpha$ actin is mainly organized according to the orientation of the cell axis and gel. The stress fibers are mostly present around the nuclear region, although some are also 
present at the extremities [80]. Actin fibers are thickened during differentiation, in both 2D and 3D cultures. Nuclei are ellipsoid in 3D conditions and are aligned with myotubes, but this is not the case in $2 \mathrm{D}$ conditions [80].

\section{Expression of integrins recognizing the RGD motif on cardiac cells}

Cardiac cells reside within one of the most mechanically dynamic environments of the body (for review [81]). Cell-integrin-ECM and cell-connexin-cell are both mechonosensors connected to the cell cytoskeleton of actin-myosin and to the cell nucleus cytoskeleton composed of laminin. The nucleus has been shown to be mechanically connected with the cytoskeleton by LINC complexes that act as a direct nuclear mechanotransducers and can regulate transcription factors and the chromatin structure. Important factors enhanced by mechanical load have been identified, such as TGF $\beta$, angiotensin II and endothelin 1 [81]. TGF $\beta$ is secreted by both cardiomyocytes and fibroblasts and is also up-regulated by angiotensin II. Decoupling the different forces by a specific set of integrin expressions in cardiac cell subtypes and spatial regulation of integrins may be a way to separate the different stimulations and functions.

In vitro, contractility of cellularized 3D scaffolds is superior in preparations associating cardiomyocyte (75\%) with fibroblast cells (25\%), but not by using only cardiomyocytes. The best results are obtained if 5\% of endothelial cells are also used in the preparations. For human hiPSC-CM, mixed preparations with other cell types are also preferable. With regard to the MSCs that are also present in the heart, in vitro, $50 \%$ of pure neonatal rat cardiomyocytes can be replaced by MSCs without any change in contractility up to one month [82]. While MSCs have a real capacity to differentiate into efficient contractile myofibroblasts, their ability to differentiate into functional mature cardiomyocytes in vitro has not been shown to be very efficient. Thus, improvements in functionality probably involve paracrine activity or interactions between MSC and other cells. There are numerous interactions between cardiomyocytes and endothelial cells during cardiac remodeling and regeneration (for review [83]). Endothelial cells improve contractility in mixed preparations, partially due to a paracrine effect of endothelial cells on cardiomyocytes, with an increased expression of both $\beta 1$ and FAK on cardiomyocytes. Co-culture of fibroblasts and cardiomyocytes is associated with a decrease in both the beating rate of cardiomyocytes and the efficiency of electrical and mechanical coupling between cardiomyocytes [84]. The presence of the cardiac myofibroblasts attenuated 
signal propagation in a stiffness-dependent manner, with a soft substrate (i.e. about $14 \mathrm{kPa}$ ) facilitating stronger and further signal transmission. As with endothelial cells, fibroblasts increase $\beta 1$ integrins on cardiomyocytes.

3.1. Key role of integrins recognizing the RGD in cardiomyocytes (for review $[34,35]$ ) (Figure 2)

Maturations of cardiomyocytes have been shown in vitro to be enhanced by co-cultures with fibroblasts and endothelial cells, mechanical stimulation, electrical stimulation, structural architecture alignment and 3D environments. Recently, the capability of neonatal or adult cardiomyocytes to synthetize laminin on collagen type I has been demonstrated both in vitro and in vivo. The local synthesis of laminin on collagen type I precedes local sarcomere organization that matches adhesion complexes [85]. The specific striation of laminin has also been reported in adult rat tissues, and descriptions provided of the specific interactions between neoformed laminin and $\beta 1$ integrins and at the level of sarcomere the same level (Fig 2) [85].

In cardiomyocytes, the most frequent integrins are $\alpha 1 \beta 1$ (for collagen), $\alpha 5 \beta 1$ (for fibronectin) and $\alpha 7 \beta 1_{D}$ (for laminin). $\alpha 6, \alpha 9 \alpha 10$ have also been detected [34]. $\beta 1$ is the dominant integrin $\beta$ chain, but $\beta 3$ and $\beta 5$ have also been reported. Two isoforms of $\beta 1$ are present in cardiomyocytes. $\beta 1 \mathrm{~A}$ is mainly expressed in embryos and $\beta 1 \mathrm{D}$ in adults [34]. The isoform $\beta 1 \mathrm{D}$ is down-regulated in post $\mathrm{MI}$ and may explain the loss of contractility. While $\alpha 5$ is the prevalent form in fetal and neonatal cardiomyocytes, $\alpha 7$ starts to be expressed after birth and is the main form in adults [34]. $\alpha 5$ and $\alpha 7$ have been shown to increase following ischemia or after MI. There is a crosstalk between different integrin expressions. In neonatal rat cardiomyocytes, upregulation of integrin $\beta 3$ upregulates the expression of integrin $\beta 1$ while downregulation of $\beta 3$ induces an inverse effect. In mice cardiomyocytes, over expression of $\alpha 7 \beta 1 \mathrm{D}$ is accompanied by an increase of integrins $\alpha 5$.

Integrins are basally expressed in two locations: they participate in the organization of sarcomeres at the level of the $\mathrm{Z}$ line (i.e. junction between different sarcomeres) and at the intercalated disk (i.e. lateral junction between cardiomyocytes). In neonatal rat cardiomyocytes, at the $\mathrm{Z}$ line, there are interactions between integrin $\alpha 2 \beta 1, \alpha$-actinin- 2 and kindlin-2. Both $\beta 1$ and $\beta 3$ have been identified at the intercalated discs and sarcomeres. To mediate signaling, $\beta 1$ integrins translocate to the intercalated disc in damaged areas of the myocardium [86]. While most integrins bind with the ECM, which is essentially composed of collagen, only $\alpha 5 \beta 1$ binds 
to fibronectin. Continuous contraction-relaxation cycles of the heart require strong and stable connections between cardiomyocytes and the cardiac extracellular matrix. In most cells, the cellular contact point with the ECM is known as the focal adhesion point (FAK) [34]. In striated muscles, the FAK equivalent is the costamere, which serves to bridge and strengthen the muscle Z-disc band and its connection with the sarcolemma membrane. The costameres are the major sites for integrin localisation. The presence of integrins at this location allows a firm physical connection between the ECM and the intracytoplasmic sarcomere. Intercalated Discs (IDC) connect myocytes end-to-end and contain structures essential for both mechanical and electrical coupling, including actin-binding adherens junctions, intermediate filament-interacting desmosomes as well as gap junctions, which mechanically and electrically couple cells. The IDC also have specific signaling as shown more recently. External mechanical forces regulate costamere assembly in cardiomyocytes. Arresting contraction can cause loss of integrins from costameres and stretching leads to an increase in integrin levels in the myocyte [87]. The sarcomeric force generation system is formed independently of environmental elasticity.

Integrins at FAK play a key role in cardiomyocyte sarcomere development and in intercalated discs. Z disc assembly starts at the cell surface in contact with FAK. Precursors of myofibrils at the sarcomere use non-muscle myosin IIB before its replacement by classical muscle myosin IIA. In mice, during development, the co-localization of $\beta 1$ integrins with vinculin appears before further costamere development [87]. The earliest associations at the $\mathrm{Z}$ band have been shown between $\alpha$-actin and titin, and vinculin and talin are the first proteins that can be observed with periodic patterning at the plasma membrane. Contractility is necessary for further sarcomere development. Similarly, inhibition of cardiomyocyte contractility leads to myofibril disassembly. During cardiomyocyte differentiation, sarcomeres increase in size and alignment and join with each other and the collagen of sarcolemma [34].

Recent studies have offered direct evidence of the pivotal role of $\beta 1$ integrins in heart stress. Using a mouse model with $\beta 1$ integrin deficiency in cardiomyocytes, global cardiac function remained normal while $\beta 1$ was reduced by $35 \%$. There was also a reduction in FAK expression level and in signaling pathways. Ventricular compaction was disturbed as well as the response to hemodynamic stress [34]. At the same time, over expression of $\beta 1$ in cardiomyocytes was observed and the heart was protected from ischemic injury with a lower infarct size. Loss of mouse cardiomyocyte talin 1 and talin 2 also led to a reduction in $\beta 1$ cardiomyocytes, costameric instability and dilated cardiomyopathy. Mice with 
inducible $\alpha 5$ transgene "gain-of-function" in cardiomyocytes have also been evaluated [88] and were found to develop arrhythmia and undergo a loss of intercellular gap junction Connexin 43 - Loss of cardiomyocytes integrin-linked kinases in mice produces an arrhythmogenic cardiomyopathy.

During hypertrophic response, $\alpha 1, \alpha 5, \beta 1$ and $\beta 3$ are upregulated and $\alpha_{\mathrm{V}} \beta 3$ and $\alpha_{\mathrm{v}} \beta 5$ are the most expressed integrins. $\beta 3$ is upregulated at the surface in RGD-stimulated cardiomyocytes. $\alpha 5 \beta 1$ is important for the hypertrophic growth and the adherence of neonatal rat cardiomyocytes. The role of integrins recognizing the RGD motif has been shown to be the prevention of cardiomyocyte cell death. In cardiomyocytes, integrins $\beta 3$ have been found to prevent cell death in the pressure-overload myocardium model. Recently it has also been shown that hypoxia upregulates $\beta 3$ integrins in cardiomyocytes and protects them from apoptosis induced by hypoxia [89]. Integrins $\beta 3$ and $\alpha \mathrm{V}$ are upregulated in the rat MI model and also during heart failure. $\alpha \mathrm{V} \beta 3$ prevents apoptosis, by increasing PTEN/Akt/mTOR and ERK1/2, and promotes proliferation. Recently, hydrogels have been shown to promote the intercalated disc assembly in engineered cardiac tissues through $\beta 1$-integrin-mediated FAK and the RhoA pathway.

3.2. Key role of integrins recognizing the RGD in fibroblasts and myofibroblasts For review [81,84,90-92] (Figure 3)

\subsubsection{General characteristics of myofibroblasts}

Fibroblasts and myofibroblasts constitute some of the abundant cellular components in the heart along with cardiomyocytes, and are thus also important quantitative cellular mechanosensors [81]. However, unlike cardiomyocytes, they have an exceptional paracrine activity enabling them to modulate ECM degradation and synthesis, and thereby to modulate stiffness. Fibroblasts are central to the adaptation of most physiological and pathological heart modifications after MI, overload, and cardiac hypertrophy. The origins of cardiac myofibroblasts are still under discussion but include proliferation and differentiation from local fibroblasts, transdifferentiation from endothelial or epithelial cells, epicardial progenitor and bone-marrow-derived MSCs [93]. Interactions between fibroblasts and the ECM, through specific integrins, mechanosensing and subtrate stiffness, are key regulators of the capacity to differentiate into highly functional contractile myofibroblasts with improved paracrine activity $[81,90,91]$. 
Tissue fibroblasts and proto-fibroblasts do not contain stress fibers, which are initially formed from cytoplasmic actin and myosin in response to mechanical stress. Intracellular stress fibers terminate in membrane integrin-containing FAK adhesion complexes that are extracellulartethered to the surrounding ECM, but also receive stress forces from the ECM. With stiffening and mechanical straining of the ECM during proto-fibroblast contraction, small initial adhesion complexes develop into large superstuctures. Transformation of fibroblasts to protomyofibroblasts is initiated by mechanical stress only. Transformation of promyofibroblasts to myofibroblasts requires force maintenance, TGF $\beta$ and fibronectin $\mathrm{A}$. The presence of collagen in the ECM and a high level of substrate stiffness promotes their differentiation. Myofibroblasts are able to synthetize a large amount of proteins and growth factors, including the essential cellular fibronectin A matrix that fibroblasts do not. Cyclic strain in fibroblasts has been shown to stimulate the production of collagen type I and fibronectin [90].

\subsubsection{Interactions with RGD ligands on the ECM directly determine the organization of the contractile apparatus in myofibroblasts (Figure $3 \mathrm{~A}$ )}

In myofibroblasts, the organization and maturation of contractile stress fibers are structurally and mechanically coupled to the formation of adhesion complexes (FAK). Strong substrate adhesion and high mechanical stress, in conjunction with biochemical cues such as TGF $\beta$ and the extracellular domain-A of fibronectin, provoke the incorporation of $\alpha$-SMA into stress fibers [90]. Functional and fully developed myofibroblasts have the ability to generate higher intracytoplasmic forces, due to the presence of $\alpha$-SMA in stress fibers, and act as a positive loop for TGF $\beta$ signaling, for increasing integrin expression, and for FAK maturation. Very developed cellular interactive sites, with the RGD binding site of the fibronectin of the ECM, are called "fibronexus". This organization is visible by means of electron microscopy and constitutes one of the main characteristics in myofibroblast identification. In ventral stress fibers, FAK complexes are present only at both extremities.

Compared with non-contractile cells, contractile myofibroblasts have a more developed classical focal adhesion complex (FAK), with an organization of stress fibers in 4 levels: ventral, dorsal, arc stress fibers and perinuclear actin caps (Figure 3A). In myofibroblasts, actin and non-muscle myosin IIA contractility is essential for the assembly of ventral and arc stress fibres [94-96]. Mechanical tension generated by acto-non muscle myosin IIA within stress fibers contributes to the assembly of both the stress fibers themselves and their associated focal 
adhesion complex. The interaction with the RGD binding site of fibronectin is necessary for promoting further maturation of the adhesion complex and the generation of higher contractile forces that allow terminal maturation of actin stress fibers with incorporation of $\alpha$-SMA. It has also been shown how actin-non-muscle myosin II contractility at the arc level is physically transmitted by non-contractile dorsal stress fibers to the adhesion complexes and associated with a secondary local rearrangement of adhesion complexes and ventral stress fibers [94]. More recently, a sarcomeric-like organization and contraction has been described in arc stress fibers in primary human myofibroblasts [94]. The highly organized actin myosin is only found in the arc stress fibers $[94,95,97]$. A sarcomeric organization was also reported earlier in a mouse tumor myofibroblastic cell line. A functional knock-out of titin in fibroblasts results in a defective myofibril assembly.

In myofibrobasts, the $\alpha 5 \beta 1$ integrins are central to this initial organization. They initially dimerize before clustering with $\alpha v \beta 3$ for an optimal response and focal complex maturation. $\alpha 5 \beta 1$ activates RhoA ROCK myosin II and $\alpha v \beta 3$ reinforces the adhesion site by inducing RhoA/mDia. RhoA ROCK regulates phosphorylation of the myosin II regulatory light chain (MKLC). Recently it has also been shown in myofibroblasts that myosin II regulation involves MLCK at the peripheral surface and ROCK in more central contractile structures [95].

\subsubsection{Integrin expression and its effect on myofibroblasts and precursors to myofibroblasts}

\subsubsection{Role of non $\alpha v$ integrins in fibroblasts and myofibroblasts}

Cardiac fibroblasts and myofibroblasts express integrins $\alpha 1 \beta 1, \alpha 2 \beta 1, \alpha 11 \beta 1$ for collagen, $\alpha 1 \beta 3$ for laminin., and $\alpha 5 \beta 1, \alpha 8 \beta 1, \alpha v \beta 1, \alpha v \beta 3$ and $\alpha v \beta 5$ for fibronectin and vitronectin.

In $2 \mathrm{D}$ culture, human cardiac fibroblasts on substrates with a low stiffness value $(2 \mathrm{kPa})$, compared with more rigid ones of $8 \mathrm{kPa}$, have higher expressions of the integrin $\alpha 2 \beta 1$ [98]. In 3D collagen gels, fibroblast adhesion is mediated mostly by the main integrin collagen receptor $\alpha 2 \beta 1$ while, under shear stress, myofibroblast differentiation depends on $\alpha 1 \beta 1$ for collagen. In SV40-immortalized mouse embryonic stem cells, cultivated in stress-attached collagen gel as opposed to floating gel, the persistence of myofibroblasts is due to the upregulation of another integrin, $\alpha 11 \beta 1$ [99]. In soft 3D collagen gel, myofibroblast maintenance requires the extremities of the gel to be attached or the preparation to be mechanically stimulated by fluids. 
Stimulation of integrins $\alpha 1 \beta 1$ and $\alpha 11 \beta 1$ was shown to be crucial for the maintenance of the myofibroblast phenotype in these experiments. We have demonstrated that a solid soft (1-3 $\mathrm{kPa}$ ) viscoelastic $3 \mathrm{D}$ collagen scaffold is sufficient for myofibroblast differentiation and maintenance, without the need for mechanical stimulation or stretching [44-46].

\subsubsection{Role of $\alpha v$ integrins in fibroblasts/myofibroblasts}

$\alpha \mathrm{v}$ integrins are expressed, and play a key role in fibroblasts and myofibroblasts by controlling the release of TGF $\beta$ and by adapting to stiffness and viscoelasticity sensing. A recent study has looked at a novel population of resident cardiac stroma cells that reside in the myocardium and exhibit a fibrogenic fate in response to cardiac ischemia. The $\alpha \mathrm{v}$ integrins were again detected in $90 \%$ of these cells and anti $\alpha \mathrm{v}$ treatment limited fibrosis after myocardial infarction by around 25\%. Resident MSCs in normal myocardium express a low level of $\alpha v \beta 3$ and $\alpha v \beta 5$ [100]. In fibrosis, there is an upregulation of these integrins in MSCs or after treatment with TGF $\beta 1$. The $\alpha \mathrm{v}$ integrins in MSCs also play an important role in the regulation of fibrosis after MI.

\subsubsection{Spatial organization of integrins in fibroblasts/myofibroblasts}

Myofibroblasts have many fundamental functions: a paracrine function, the control of tissue fibrosis and regeneration by controlling TGF $\beta$ signaling, control of ECM stiffness and degradation, synthesis of fibronectin and collagen for ECM. The spatial regulation and specific set of integrin expressions may help to regulate these different functions in a separate manner (Figure 3B).

At the cell periphery, integrins that classically recognize a cyclic RGD peptide are present and involved in the control of fibrosis by controlling the release of TGF $\beta$ from latent TGF $\beta$. At the main basal contacts with ECM, especially at FAK adhesion complexes at the extremity of the dorsal stress bands or ventral stress fibers, interactions with $\beta 1$ integrins are predominant. Depending on the type of associated $\alpha$ chains, $\beta 1$ integrins can recognize: $1^{\circ}$ ) the collagen that is associated with $\alpha 1$ or $\alpha 2$ (i.e. $\alpha 1 \beta 1$ or $\alpha 2 \beta 1$ ); $2^{\circ}$ ) the linear RGD peptide of fibronectin (if associated with $\alpha 5$ (i.e. $\alpha 5 \beta 1$ )). Engagement of $\alpha 5 \beta 1$ and force leads to more elaborate focal adhesion sites by recruiting $\alpha v \beta 3$ and $\alpha v \beta 5$. These latter integrins play a fundamental role in a complex stabilization process but also in sensing viscoelasticity, curvature, stiffness, and the ultrastructural fibrillary structure of collagen microarchitecture. Il6 
is a well-known profibrotic cytokine involved in heart fibrosis and stimulates TGF $\beta$ signaling. Recently it has been shown how substrate stiffness, by interacting with integrin $\alpha 2 \beta 1$, is able to control Il6 release.

\subsubsection{TGF $\beta$ fibroblasts and integrins}

There are positive crosstalks and activation loops between TGF $\beta$ and integrin expressions and functionalities [101]. TGF $\beta$ is secreted with its non-covalent bound latencyassociated peptide (LAP) in a large complex that covalently links LAP to $\alpha 5$ TGF $\beta 1$ binding protein, LTBP-1. The cardiac normal ECM is rich in TGF $\beta 1$, that is bound to the large latent complex. The TGF $\beta$ can be released through contraction-mediated conformational changes and opening of latent complex after interaction between cell integrin receptors (i.e. $\alpha v \beta 3, \alpha v \beta 5$, $\alpha v \beta 6$ and $\alpha v \beta 8$ ) and a RGD peptide present on the latent complex (Figure 3) or by numerous other mechanisms, including MMP2 and/or MMP9 proteolytic cleavage. Integrin-mediated cell pulling induces conformational changes in the LAP of TGF $\beta 1$ and TGF $\beta 3$, leading to the release of active TGF $\beta 1$ on a rigid substrate [90]. While blocking TGF $\beta$ does not block fibrosis, blocking $\alpha \mathrm{v}$ does block fibrosis in vivo. In fibroblasts, the stimulation of integrins recognizing the RGD peptide, as with TGF $\beta 1$, shares some common signaling with an increase of Src and p38 that leads to an increase in $\alpha$-SMA and then generates higher intracellular forces [91]. Collagen and $\beta 1$ integrins or/and the fibroblast growth factor (FGF) increase FAK and then ERK, which is an inhibitor of $\alpha$-SMA. However, at the same time, ERK is an activator of intercellular cadherin OB-Cadherin and thus enhances intercellular transmission [91]. Intercellular junctional cadherin increases $\beta$-catenin, which is normally inhibited by Wnt/frizzled/pGSK-3 $\beta$, and this also leads to an increase in OB-cadherin and intracellular force [91]. Recently, YAP and TAZ cytoplasmic transcription factors have been shown to be critically important in mechanosensing from the ECM, cell adhesion sites and cell shape. Actinmyosin cytoskeleton contraction is associated with the nuclear translocation of the YAP/TAZ complex to the nucleus, where it contributes to the regulation of gene expression, including increased TGF $\beta$ signaling and integrin expression. Upregulation of YAP/TAZ increases myofibroblast differentiation [90].

\subsubsection{Key role of integrins recognizing the RGD motif on myofibroblasts during collagen fibrillogenesis}


The fundamental role of the cardiac fibroblasts is to maintain and adapt ventricular stiffness in pathophysiological conditions and to maintain ECM composition. One key function of myofibroblasts is their role in collagen fibrillogenesis. After MI, after activation and transformation into myofibroblasts, they secrete a new ECM matrix made of cellular fibronectin A and collagen to replace the provisional non-cellular fibronectin made of plasmatic fibronectin. This replacement is necessary to prevent cardiac rupture. The first step of ECM synthesis is the preparation of a first provisional matrix, made of cellular fibronectin A, before incorporation of the collagen for matrix reinforcement. The capability of the myofibroblasts to interact with a RGD site is crucial in these two events. Unlike other ECM components that are capable of self-polymerization, the polymerization of fibronectin is dependent upon its interaction with cell surface receptors (i.e. $\alpha 5 \beta 1$ integrins) present in the myofibroblasts. It is important for the fibroblasts to mechanically unfold the fibronectin in order to expose critical cryptic sites on fibronectin necessary for interaction with other fibronectin molecules and for polymerization. The initiation of the addition of collagen to a provisional fibronectin matrix is also dependent on the capacity of the fibroblasts to mechanically unfold the fibronectin to expose specific binding sites for collagen I.

\subsubsection{Key role of integrins recognizing the RGD on fibroblasts and myofibroblasts during heart fibrosis and postinfart healing}

The expression of $\alpha 5 \beta 1$, the classical fibronectin receptor, is increased in fibrotic tissue and the downstream signaling of $\alpha 5 \beta 1$ promotes the expression of additional fibronectin in an example of a positive loop [100]. Auto secretion of fibronectin by activated fibroblasts in the presence of stress and TGF $\beta$ contributes to further myofibroblast differentiation by initiating signaling through FAK, which facilitates the formation of elaborate and mature integrin adhesions with clustering and increases stiffness by secreting collagen. Another fibronectin binding protein, $\alpha 8 \beta 1$ integrin, is specifically expressed in myofibroblasts within fibrotic hearts. Overall, $\beta 1$ integrins are increased in fibrotic hearts and specific deletion of $\beta 1$ in fibroblasts causes insufficient wound healing and a reduction in myofibroblasts, resulting in impaired heart healing after MI with cardiac rupture.

Other important integrins, directly linked to mechano-transduction and myofibroblast differentiation, are the $\beta 3$ integrins that recognize the RGD motif [73][82]. $\beta 3$ integrin expression is increased after MI and is necessary in cardiac fibroblasts for the accumulation of collagen and fibronectin in response to pressure overload. This effect is mediated by the FAK 
component talin, which links integrins to the cytoskeleton and is required for integrin $\alpha v \beta 3$ mechano-transduction. Talin1 is expressed in the heart during development and in cardiac diseases and its deletion alters the p38, ERK1/2, Akt and GSK-3 $\beta$. All these kinases are involved in TGF $\beta$, inducing myofibroblast differentiation and accumulation of $\alpha$-SMA in stress fibers, which increases intracellular mechanical tension [91]. $\beta 3$ integrin involvement with ECM signaling through Src and p38 further promotes the expression of $\alpha$-SMA and $\beta 3$, thus forming additional positive loops. Important crosstalk between integrins, TGF $\beta$ and canonicalWnt signaling has been reported in cardiac myofibroblasts. It has been shown that $\beta 3$ integrins, like TGF $\beta 1$, activate Src and p38 and thus promote $\alpha$-SMA expression [91]. The $\beta 1$ integrins activate the factors FAK and ERK and then promote $\alpha$-SMA expression [91]. ERK inhibits canonical Wnt /GSK-3 $\beta$ signaling and promotes the OB-cadherin of Wnt signaling, resulting in the transmission of higher intercellular forces [91].

3.3 Key role of integrins recognizing the RGD in endothelial cells For review on integrins during angiogenesis [48,83]

Angiogenesis is critical for tissue engineering to improve implant survival following implantation and for allowing the generation of scaffolds with a greater thickness. With regard to the realization of contractile scaffold in vitro, the presence of endothelial cells surprisingly increases the contractility of associated cardiomyocytes by a paracrine action through enhancement of $\beta 1$ integrin [102]. For angiogenesis, it has been shown that it is necessary to have a scaffold with a minimal pore size of 20-30 $\mu \mathrm{m}$ for cellular colonisation. Recently the $\alpha_{V} \beta 3$ integrins have been shown to mark regenerative peri-infarct zone after MI in human endothelial cells and the intensity of the mark is a predictor of a favorable outcome and a limited infarct.

\subsubsection{Role of integrins recognizing the RGD during vasculature development}

$\alpha 5$ and $\alpha v$ integrins play a key role during vasculature development. Fibronectin is one of the first ECM proteins to be expressed around the vasculature and is essential for cardiovascular development. In its absence, $\alpha v$ integrins (i.e. $\alpha v \beta 1, \alpha v \beta 3, \alpha v \beta 5, \alpha v \beta 6, \alpha v \beta 8$ ) can be relocated towards focal contacts previously occupied by $\alpha 5 \beta 1$ and assembled fibronectin [103]. Genetic ablation of $\alpha 5$, or its major ligand fibronectin, leads to embryonic lethality due to severe cardiovascular defects of the heart, dorsal aorta and yolk vasculature. 
However, specific deletion of $\alpha \mathrm{v}$ and $\alpha 5$ in endothelial cells failed to induce any defect of the vasculature but leads to defects in the remodeling of heart and great vessels.

\subsubsection{Integrin expression on endothelial cells during angiogenesis: key role of integrins recognizing the RGD}

$\alpha 5 \beta 1$ integrins are poorly expressed on quiescent adult endothelium but are upregulated during development and angiogenesis [104, 105][152, 153]. Angiogenesis is the growth of new blood vessels form preexisting blood vessels. Angiogenesis involves four phases: 1) stimulation and basement membrane breakdown, 2) sprouting, 3) tube formation and 4) maturation [48]. Integrins $\alpha 5 \beta 1 \alpha v \beta 3$ regulate the same pathways during angiogenesis. These pathways are distinct from those regulated by $\alpha v \beta 5$ integrins. $\alpha_{v} \beta 3$ interacts with growth factor bFGF, while $\alpha_{v} \beta 5$ interacts with VEGF.

In their quiescent state, endothelial cells (EC) adhere to the basement membrane made of collagen type IV and laminin through integrins: $\alpha 1 \beta 1, \alpha 2 \beta 1, \alpha 6 \beta 1$. The integrins $\alpha 1 \beta 1, \alpha 2 \beta 1$, $\alpha v \beta 3$ and $\alpha 9 \beta 1$ on EC have been shown to be directly involved in the initial response to various proangiogenic factors, thereby stimulating basal membrane breakdown. Basement membrane breakdown exposes the interstitial provisional matrix of collagen type I, fibronectin, fibrin and vitronectin proteins that promote initial sprouting by interacting with integrins $\alpha 1 \beta 1, \alpha 2 \beta 1$, $\alpha 3 \beta 1$ and with those integrins recognizing the RGD motif, i.e. $\alpha 5 \beta 1, \alpha v \beta 3$, $\alpha v \beta 5$ [48]. The interstitial collagen, fibrin and laminin support tube formation by interacting with integrins: $\alpha 2 \beta 1, \alpha 5 \beta 1$, and $\alpha v \beta 3$ and $\alpha 6 \beta 1$. During maturation, the ECM basement membrane begins to recover its initial composition of collagen IV and laminin and, along the sprout, pericytes are found. A new set of integrins are also observed along the sprout: $\alpha 1 \beta 1, \alpha 2 \beta 1, \alpha 4 \beta 1, \alpha 6 \beta 1$ and $\alpha 6 \beta 4$ [48]. As for the specific role of integrins recognizing the RGD motif during angiogenesis, it has been shown that: $\alpha 5 \beta 1$ promotes endothelial cell migration, tube formation and the promotion of mature vasculature, $\alpha \mathrm{v} \beta 5$ supports endothelial cell migration and tube formation, and $\alpha v \beta 3$ supports endothelial cell migration and tube formation, but with an immature and leaky network. Hypoxia has been shown to increase the level of $\alpha_{\mathrm{V}}, \beta 1, \beta 3, \beta 5$ and $\alpha 5$ and to promote their migration and capillary-like tube formation in human microvascular endothelial cells by stimulating HIF.

\subsection{Key role of integrins recognizing the RGD in multipotent mesenchymal stem cells (MSC)}


MSCs have been shown to give rise to many types of heart cells, especially fibroblasts/myofibroblasts and endothelial cells. The capability of MSCs to give rise to mature functional contractile cardiomyocytes has not been clearly demonstrated. Regarding MSCs, under $2 \mathrm{D}$ and $3 \mathrm{D}$ conditions, ligand binding, stiffness, and viscoelasticity are independent factors that control their differentiation potential. MSCs appear more likely to differentiate for stiffness levels below $1 \mathrm{kPa}$ in adipocytes, between 3 and $25 \mathrm{kPa}$ in smooth muscle cells, and of more than $30 \mathrm{kPa}$ (the most rigid) in osteocytes [106]. Substrates of intermediate rigidity induce over expression in integrins $\beta 1, \alpha 3$ and $\alpha 7$. Myosin type IIA and IIB content is increased with stiffness. MyoD is upregulated in substrates of intermediate stiffness [106].

\subsubsection{Expression of integrins in MSC}

Cultured MSCs are positive for the surface markers CD44, CD73, CD90, CD105, CD106, CD120a, and CD124. MSCs have to establish appropriate contacts with the ECM in bone marrow, which is mainly composed of collagen types I and IV and fibronectin. They express various integrin subunits such as $\alpha 1, \alpha 2, \alpha 3, \alpha 4, \alpha 5, \alpha 6, \alpha 7, \alpha 10, \alpha \mathrm{V}, \alpha \mathrm{IIb}, \beta 1, \beta 3, \beta 4$, and $\beta 5 \beta 1$ [107]. Integrins recognizing collagen $\alpha 2 \beta 1$ and $\alpha 11 \beta 1$ have been found to promote the survival of MSCs on collagen I [108]. MSC migration is regulated by fibronectin through $\alpha 5 \beta 1$-integrin-mediated activation of PDGFR- $\beta$ and the potentiation of growth factor signals. $\alpha 4 \beta 1$ has been shown to be of particular importance for rolling and firm adhesion of MSCs on the endothelium. The platelet-derived growth factor is important in inducing differentiation of MSCs towards myofibroblasts. Mice with depleted $\alpha \mathrm{v}$ integrins are protected against fibrosis in cardiac muscle [109]. In spontaneously hypertensive rats with spontaneous fibrosis, there is an upregulation of TGF- $\beta 1, \alpha v \beta 5$, Smad $2 / 3$ and $\alpha$-SMA in MSCs. The specific inhibition of $\alpha v \beta 5$ prevents tissue cardiac fibrosis.

\subsubsection{MSC paracrine functionality}

MSCs have an exceptional paracrine functionality but it needs to be induced to become optimal. Inflammatory cytokines, hypoxia and LPS, have been shown to prime MSCs. It is generally accepted that MSC immunomodulation is strongly induced by cytokines in the inflammatory environment, particularly by IFN gamma (IFN $\gamma$ ) and inflammatory cytokines such as IL-1 $\alpha$, IL-1 $\beta$, TNF $\alpha$ or LPS. Their therapeutic effect is mainly mediated by paracrine mechanisms through the release of soluble factors, including exosome. 
MSC paracrine activity has been shown to be enhanced in 3D conditions such as 3D spheroid cell cultures [110]. Our own research [44] and that of others [47] has reported how MSC paracrine functionality is enhanced if the MSCs are cultured in solid 3D collagen scaffolds instead of under classical 2D conditions using collagen. We have also reported that the paracrine potential of MSCs is not altered following differentiation in contractile myofibroblasts [44]. While the paracrine activity of MSCs, and especially their immunosuppressive paracrine potential, is improved in comparison with that observed using cultured MSCs in 2D conditions on plates coated with collagen, the level of synthesis of proteins such as fibronectin or collagen I is lower in 3D than in 2D conditions [47].

\subsubsection{Improving interaction with integrins recognizing the RGD in MSC may improve therapy with MSC after MI}

Thanks to the exceptional paracrine function and low immunogenicity, it has been proposed to use MSCs after MI [111]. However, the paracrine function of MSCs is altered after implantation onto the infarct areas. Thus, transplantation of MSCs in a cellularized patch rather than by a direct intramyocardial injection, may be a way of controlling and maintaining their microenvironment.

In animal models, direct injection of MSCs into the myocardium failed to improve the ventricular contractile function after MI, due to significant cell death. However, their survival and efficacy can be enhanced if the cells are transfected with surviving genes such as Akt [112], Bcl2 [113], Ilk [114] or periostin that contains RGD [115]. In a synthetic 3D PEG scaffold, the presence of RGD was shown to improve MSC survival [116] on condition that it is covalently linked to the scaffold and presented with a small spacer arm of glycine chains. The RGD interactions were found to activate surviving genes such as Ilk and Akt. Human MSCs were applied to the infarct area by means of a collagen patch, very early after MI, and produced an effect that was superior to that observed when MSCs were injected directly into the myocardium. The collagen patch with MSCs was accompanied by increased angiogenesis and a decrease in left diastolic pressure [117]. However, the use of MSCs was not optimal because in this experiment MSCs were not primed [117]. MSCs have also been used with collagen type I gel after 2 weeks of culture and then applied on a semi-recent 1-month infarct. No increase in ventricle function was reported except for an increased local angiogenesis [118]. The principal paracrine effect of MSCs after MI is an anti-apoptotic effect on cardiomyocytes, promoting the switch of macrophages from M1 to M2, and the promotion of neoangiogenesis. The paracrine 
effect on macrophages was lost if the transplantation was performed after 4 days, with a maximum beneficial effect after 2 days.

\subsection{Key role of integrins recognizing the RGD in resident somatic cardiac multipotent stem cells}

The expression of integrins in human somatic multipotent stem cells isolated from heart biopsies has been reviewed recently [54]. In the heart, resident progenitors are present only in the epicardial layer and are surrounded by fibronectin [25]. Fibronectin, especially the RGD, is essential for the reparative potential of the resident cardiac progenitor stem after MI [25].

\subsubsection{Integrins in human c-kit positive cardiac multipotent stem cells "MASC":}

In 3D collagen scaffolds, in vitro, with MASC, a high level of expression of collagen receptor $\alpha 2 \beta 1$ integrin has been reported as well as a high level of TGF $\beta$ secretion [119].

\subsubsection{Integrins in multipotent stem cell populations such as "cardiospheres"}

Cardiospheres are composed of mixed populations of Cardiac c-kit+ stem cells, multipotent MSCs and endothelial cells. It has been shown that the number of c-kit+ stem cells is low and does not determine their most important functionality. In addition to MSCs, "cardiospheres" are one of the most promising cell types for improving outcome after MI. As with MSCs, their paracrine functionality is essential. Previous studies have shown the importance of cell/cell contacts, present only in the 3D clusters, among the therapeutic benefits of cardiospheres. With clusters in cardiospheres, as opposed to monolayers, there is an enhanced expression of ECM protein (collagen, laminin) and $\alpha 2$ integrins [120]. When compared with the monolayer counterpart, cardiospheres in clusters present enhanced engraftments and a better therapeutic outcome for acute MI in mouse and pig [121]. We have reported in vitro how human cardiospheres in clusters, seeded in 3D collagen functionalized with the RGD peptide, enhanced their differentiation towards cardiomyocytes compared with cardiosphere clusters alone or those seeded in 3D solid gelatin scaffolds [40]. More recently, the attachment, retention and therapeutic benefits of human cardiospheres, injected intramyocardially in SCID mouse models immediately after MI, have been found to be dependent on $\beta 3$ (i.e. recognizing the RGD) and susceptible to attachment to fibronectin [20].

\subsection{Expression of integrins in cardiomyocytes obtained from totipotent embryonic stem cells: ESC-CM or iESC-CM}


Fibronectin containing the RGD peptide is able to drive some 3D constructs of pluripotent stem cells towards endothelial cells, while laminin pushes them towards a myocyte path. Some studies have demonstrated the key role of integrin $\alpha 6$ and $\beta 1$ (i.e. laminin) with respect to cardiomyocyte lineage. Mouse cardiomyocytes derived from iPSC (iPSC-CM) have been observed to express collagen type I, $\alpha 1$ and $\beta 1$. Beating cardiomyocytes derived from human embryonic stem cell hESC-CM have been found to be embedded in a variety of ECM proteins (i.e. collagen (IV, XVIII), laminin (LN1, LN8, LN10) and fibronectin. When hESCCM were transplanted into SCID mouse myocardium, local enrichment was reported in collagen IV and XVIII and for integrins ( $\alpha 3, \alpha 5, \alpha 6, \alpha 7, \alpha 11, \alpha \mathrm{v})$ and $\beta 1$ [122]. Following long-term in vivo implantation, an increase in $\alpha 3$ and decreases in $\alpha 5, \alpha 6$, and $\alpha \mathrm{v}$ were observed [122].

\section{Key role of integrins recognizing the RGD motif during cardiac development}

During cardiac development, cells interact with cardiac jelly that is enriched in fibronectin, laminin, and different types of collagen, especially collagen I. Collagen IV binds BMP4 and regulates BMP signaling. This matrix is enriched in hyaluronic acid and proteoglycans that render it highly hydrated and malleable. Type I collagen predominates at each step of development. In mouse heart, type I collagen predominates in the early stages and is then associated with type III collagen. In the adult heart, density and crosslinking of collagen increases its stiffness. The elastin level is relatively low during development but increases in the adult heart. Collagen IV is present at all stages and increases after birth. Compared with the fetal myocardium, in the adult myocardium the ratio of collagen I to collagen III is increased and its density and crosslink are higher. In the adult myocardium, type I collagen is the major component of interstitium and represents $85-90 \%$ of all collagen content. Collagen type I is predominantly present in the epimysium and perimysium. In contrast, collagen type III represents $5-11 \%$ of total collagen and is more prominent in the endomysium in direct contact with cardiomyocytes (Figure 2). Fibronectin is decreased in the adult with a concomitant increase in elastin. The fibronectin is limited to the basal lamina [123]. Laminin is expressed throughout the myocardium and cardiomyocytes secrete their own laminin at the basement membrane for the contractile apparatus assembly. These changes are accompanied by an increase in cardiac stiffness that is 3 times more in the adult myocardium (10 to $20 \mathrm{kPa}$ ) than that found in the fetal myocardium. 
Numerous studies have shown the importance of integrins during cardiomyogenesis, particularly $\alpha 4, \alpha 5$ and $\beta 1$. Global deletion of $\beta 1$ is lethal at E5.5, while cardiac deletion of $\beta 1$ leads to a variety of cardiac defects. During development, fibronectin has been shown to mediate mesodermal fate decisions by regulating Wnt signaling in mesodermal cells through the activation of integrin- $\beta 1$ [124]. Although $\alpha 5 \beta 1$ integrins are thought to be the primary receptors of fibronectin, mice lacking integrin $\alpha 5$ have less severe developmental defects than those lacking fibronectin. In 2D cultures, preparations associating laminin and fibronectin have a higher efficiency level for stem cell differentiation. ESCs cultured in the 3D ECM construct of laminin or vitronectin also differentiate more efficiently than ESCs cultured in 2D. Collagen type I, by interacting with $\beta 1$ integrins, supports the maturation of porcine and human iPSCderived cardiomyocytes. Similarly, fibronectin promotes cardiac mesoderm differentiation through $\beta 1$ (i.e. $\alpha 5 \beta 1$ ) and activation of the $\mathrm{Wnt} / \beta$-catenin pathway.

While the 3D collagen type I hydrogel support failed to promote differentiation of human sca- $1+$ cells towards cardiomyocytes [125], we found that using porous, solid DHT collagen type I and type III scaffolds, with a stiffness of around $1 \mathrm{kPa}$ and functionalized with the RGD peptide, were able to enhance differentiation of human cardiospheres towards cardiomyocytes [40].

\section{Key role of integrins recognizing the RGD after MI For review $[3,4]$}

Integrins are at the interface between cells and ECM and, as mechanoreceptors, they play a key role in all heart physiological and pathological adaptations. Integrins on cardiac cells are thus directly involved in the different healing and remodeling phases after MI. The cardiac ECM does not simply serve as a structural scaffold but also transduces molecular signals and plays an active role in the regulation of inflammatory and reparative processes. ECM serves as a reservoir for growth factors and proteases that can be released following injury. Fragmentation of the ECM provides key stimuli for the inflammatory cascade. The release of collagen and fibronectin fragments acts as a proactive inflammatory stimulus [4]. TGF $\beta$ plays a crucial role after MI in controlling cardiomyocyte survival and hypertrophic response, in the activation of fibroblasts and the differentiation to myofibroblasts with new ECM synthesis, and in the activation of a matrix preserving program and its anti-inflammatory effects [126].

Integrins recognizing the RGD motif have been shown to play a key role after MI, with a specific expression in the cells in the peri-infarct regenerative area. In adult rat heart without MI, there is no expression of $\alpha 1$, moderate expression of $\alpha 3$ and only slight expression of $\alpha 5$. 
In the first week after MI, the $\alpha 1$ subunit, collagen and fibronectin increase only in the periinfarct area, while the $\alpha 5$ (for RGD) subunits increase in both peri infarcted and non-infarcted areas. At 42 days, $\alpha 1$ and collagen are still increasing while fibronectin and $\alpha 5$ are decreasing. Integrins $\beta 1$ and $\beta 3$ have a low expression basally that increases at the peri-infarct zone at 3 days post-MI, peaking at 7 days, and then declining to the base line [127]. $\beta 1$ also increases in the remote myocardium after MI. $\beta 1 \mathrm{~A}$ isoform is found in fibroblasts and inflammatory cells, while $\beta 1 \mathrm{D}$ is found in cardiomyocytes. $\beta 3$ is mainly found in endothelial cells and smooth vessel cells in the peri-infarct area. The heart of integrin $\beta 1 \mathrm{KO}$ animals have a lower contractility after MI, increased apoptosis and fibrosis. $\alpha \mathrm{v} \beta 3$ imaging is currently the most frequently used method to visualize neo-angiogenesis in vivo. Its expression is low in normal tissue, but becomes expressed in activated endothelial cells during angiogenesis in the human infarct myocardium [21]. In rat models of MI, the capture of RGD increases at 3 days, peaks at $1-\mathrm{w}$, remains stable up to $3-\mathrm{w}$, and then decreases after 6 months. Increased uptake at $1 \mathrm{w}$ is associated with a long-term decrease in infarct size, an improved ejection fraction and decreased remodeling [21]. On histological sections, cells expressing $\beta 3$ are present in endothelial cells in the border zone, but not in the remote myocardium [21, 22]. The uptake is increased in the infarcted region and acts as a biomarker for cardiac repair. It can also predict region recovery [23].

During the reparative phase, after 7 days in humans, local macrophages switch their phenotype M1 to M2, with augmented expression of anti-inflammatory, pro-fibrotic and angiogenic factors such as IL-10, TGF- $\beta$ and VEGF. The deposition of de novo ECM of cellular fibronectin and collagen, by the specialized myofibroblasts that replace the provisional initial plasma fibronectin matrix, is necessary to maintain structural stability and this requires the switch from inflammatory to pro-fibrotic signaling factors. TGF $\beta 1$ inhibits initial detersive inflammation and promotes the differentiation of fibroblasts into myofibroblasts and the accumulation of dense ECM in the myocardium interstitium. During the proliferative phase of MI healing, the ECM fibrin/collagen is enriched through the deposition of a wide range of structurally diverse "matricellular proteins" that do not play a direct structural role but act by regulating cytokines and growth factor responses and by modulating cell phenotypes and functions. The main matricelluar proteins are periostin, tenascin, thrombospondins, secreted protein that is acidic and rich in cysteine (SPARC), and osteopontin. Most of these proteins 
have a RGD motif in their structure and this RGD site is specifically involved in their main functionality after MI.

An antagonist for cyclic RGD (i.e. $\alpha v \beta 1, \alpha v \beta 3, \alpha v \beta 5$ ) was injected intravenously in mice 7 days after MI and for 7 days. There was a 58\% decrease in MI size and interstitial fibrosis intensity decreased from $36 \%$ to $15 \%$ without any appearance of early cardiac rupture [128].

\section{Different approaches for cardiac cell delivery after MI}

After MI, the main cellular effects after cell transfers are not due to the contractile properties of the preparations, but more to the paracrine capabilities of associated cells, whether they are contractile or not. In general, a tissue engineering/regenerative medicine approach consists of seeding cells in a scaffold, followed by in vitro tissue maturation and construct implantation in the host environment. However, alternative approaches exist, but lack some elements or steps such as (i) cell injection with or without a scaffold (no in vitro maturation) and (ii) scaffolds that attract endogenous cells (no cells and in vitro maturation). All these approaches involve the design of a pre-formed or injectable scaffold, using a biomaterial able to properly interact with seeded or endogenous recruited cells. Therefore, surface functionalization can be employed in both seeded and unseeded scaffolds.

\subsection{Use of cells associated with a 3D scaffold for tissue engineering and cell transfer}

An ideal 3D scaffold should provide: 1) biomimetic diversity of binding sites to engage functionally relevant integrins in both cardiomyocytes and non-myocytes; 2) sufficient numbers of cell-binding sites to permit a physiological tissue density; 3) capacity for significant remodeling of tissue structure to allow rapid cell spreading, alignment and replacement of original with cell-secreted ECM; 4) appropriate biomechanical properties to enable continuous tissue contraction; 5) minimal immunogenicity when transplanted in vivo; and 6) stability to allow generation and implantation of tissues of clinically relevant size.

The development of suitable biodegradable biomaterials as candidates for cardiac tissue engineering is an active field of research. Different methods are continuously studied to develop three-dimensional scaffolds with a specific shape, thickness, mechanical strength, and porosity to promote cell growth. The specific physical properties of constructs that are crucial for the success of this approach are biocompatibility, the chemical composition of the polymers, possibility of absorbing proteins, surface energy, adhesion molecules, ability to foster cells, tailored degradation rate, permeability (for biomolecule diffusion), natural or non natural 
components, adhesion molecules, porosity, ability to absorb proteins, suitable mechanical properties (stiffness [129], viscoelasticity [74, 75]), ultrastructural properties (orientation, roughness, fibrillary network) [78], nanotopography [130], contractility and electrophysiological stability, toxicity degradation, low immunogenicity, ability to promote angiogenesis, ability to engineer a thick scaffold of sufficient size, clinically safety, stability (for recent reviews [16,131,132]).

Biomaterials are designed to mimic the intricate native cardiac ECM, mainly composed of collagen. Common methods include the control of the mechanical properties of the material, incorporative bioactive signals, spatially patterning bioactive signals and the controlled release of bioactive signals. Both natural polymers (collagen type I monomers, gelatin), fibrin glue (fibrinogen), natural polysaccharides, such as alginate/chitosan/hyaluronic acid, and synthetic polymers have been used. The best results so far have been achieved with natural polymers. Natural materials such as collagen, fibrin or synthetic polyglycolic acid have been widely investigated, and some novel compositions (i.e. silk fibroin and hyaluronic acid, alginate/chitosan polyelectrolyte complexes) have recently been introduced. Despite the fact that they show the required biocompatible behavior, most synthetic polymers exhibit a poor cell attachment capability. These synthetic polymers are mostly hydrophobic and lack cell recognition sites, limiting their applications. Therefore, biofunctionalization of these biomaterials to enhance cell attachment and cell material interaction is being widely investigated [133, 134]. It is the same for natural polymers composed of polysaccharides (such as alginate/chitosan/hyaluronic acid) that lack adhesion molecules and have a low propensity for spontaneous protein adsorptions. Various materials have been tested, including 3D gel or solid 3D porous sponges made of alginate, collagen or gelatin, polyglycolic acid, poly-l-lactic acid/polyglycolic acid composites, and poly(glycerol sebacate). An obvious advantage of solid scaffolds when compared with gels is the ease of engineering any desired 3D forms and thickness for a prolonged period of time. The solid scaffold may also facilitate cell transfer. Complex micro tissues have also been obtained in synthetic poly(glycerol sebace) seeded with cardiac fibroblasts and neonatal cardiomyocytes. Beating cardiomyocytes have been reported but true contractility of the structure with force and displacement was not clearly demonstrated [135].

Recent advances in nanomaterial technology drive the design of more complex microenvironments mimicking those of native myocardium. Specifically, sophisticated methods for electrospinning and 3D bioprinting offer the ability to use natural and/or synthetic 
biomaterials and to control scaffold architecture and cellular composition in a spatially precise fashion [132]. Electrospinning involves extrusion of electrically-charged polymers through a small orifice to create nanofibers with precisely controlled dimensions and the ability to generate higher-order 3D geometries based on fiber collection methodologies. No contractility has been demonstrated even in composite scaffolds. Most electrospinning studies have utilized synthetic polymers (PLGA, Polycaprolactone (PCL). Recent methodological advances have permitted increased incorporation of native proteins (e.g. gelatin, collagen) into electrospun nanofibers. There are several limitations that must be overcome, however, to enable the generation of highly functional and therapeutically relevant contractile tissue using the electrospinning approach. These include: 1) low porosity that precludes deep penetration of seeded cells; 2) inability to efficiently incorporate various cardiac ECM proteins, 3) very stiff constructs (around $1000 \mathrm{kPa}$ ), while the optimal stiffness for cardiac tissue engineering is around $10-20 \mathrm{kPa} ; 3$ ) the ultrastructure of the collagen fibers that are lost; 4) very small size pores (around 1-3 $\mu \mathrm{M}$ ), limiting cellular colonization. The new 3D bioprinting technology allows the fabrication of contractile tissues even with the association of natural and synthetic biomaterial polymers. Early work utilized RGD-conjugated alginate or HA/alginate matrices with human cardiac progenitor cells (hCPCs) to 3D-print. 3D printing technology has found applicability in the fields of tissue engineering and regenerative medicine in the form of bioprinting. Bioprinting involves the process of laying down cells in a predefined spatial arrangement with or without use of a biocompatible scaffold, using 3D printing technology. In order to result in functional tissue, the cells must maintain their viability and specific cell function within their new environment. 3D bioprinting strategy to create functional cardiac tissue capable of synchronized contractions, a characteristic of native myocardium, has been demonstrated, although tissue thickness is still very low. After 3 weeks of culture with neonatal rat cardiomyocytes in bioprint hydrogels of fibrin/hyaluronic acid and gelatin, a developed force of $2 \mathrm{mN}$ was reported. The entire construct is $1.8 \times 1.6 \mathrm{~cm} 2$ with a $0.6 \mathrm{~mm}$ thickness [136]. More recently, an oriented cardiac microtissue with neonatal rat cardiomyocytes was fabricated by bioprinting with poly(ethylene glycerol, polydimethylsiloxane (PMDS), and Gelatin methacrylate. Scaffold stiffness was high, around $148 \mathrm{kPa}$. A thin construct of less than $100 \mu \mathrm{M}$ was fabricated. A small displacement of around $10 \mu \mathrm{m}$ was observed with a maximum developed force of $14 \mathrm{mN} / \mathrm{mn} 2$ [137].

\subsection{Possible transfer of cells in a 3D construct without a 3D scaffold}

\subsubsection{Culture of cells in vitro as a 3D cell cluster: "Spheroids approach"}


The development of cardiac cells as 3D clusters has been shown to be an efficient method for cardiac cell isolation, amplification and transfer. This approach has been used for human "cardiosphere" isolation and amplification and to enhance cell paracrine functionality. The culture of cardiac cells as a 3D cluster is a way of enhancing cell-cell interaction. A neo ECM has also been studied. The major drawback is the lack of functional and homogenous architecture, so that there is no construct contractility. Achieving a uniform distribution of the cluster at the time of cell delivery is not trivial. In some cases, the association of spheroid cells with 3D scaffolds can improve their transfer to myocardial or epicardial locations.

\subsection{2 . Cell sheet technology}

Cardiac myocytes cultured on standard plastic dishes for extended periods tend to detach from the substrate as a more or less intact monolayer. Several monolayers can be overlaid to form 3D structures. Shimizu et al. have exploited this principle in developing temperaturesensitive coating materials that allow cell monolayers to detach, intact, from the culture surface at room temperature [138]. Stacking of several cell sheets generates 3D tissues that beat and develop force. One limitation of this approach is that diffusion is limited to a few cell sheets (total thickness of about $50 \mu \mathrm{M}$ ) and angiogenesis is poor. With this approach, using human iPSC-derived cardiac cells in fibrin sheets, the contractile force is $0.85 \mathrm{mN}$ and the thickness $21.5 \mu \mathrm{m}[138]$.

\section{Contractility in cellularized 3D scaffolds}

To date, contractility has only been reported after seeding cells in natural polymers/tissues containing collagen (collagen/gelatin/decellularized tissues), fibrin or Matrigel, but not for natural alginate or synthetic materials. The contractility has been reported with preparations of hydrogels, gels and solids.

Contractile cardiac tissues can be constructed: (1) by seeding the cells onto ECM of decellularized myocardial tissue; (2) by suspending cells in a 3D scaffold. Mechanical forces have been shown to guide cardiogenesis [79] and to control contractile cardiac development [90]. It has been shown that engineered contractile tissue could be transplanted into the heart surface epicardium. At this location, the preparations were observed to survive and to become vascularized and even functionally, electrically and mechanically integrated. So far, contractility has only been reported for natural scaffolds containing collagen (collagen, gelatin (i.e. denatured collagen but with very poor structural properties) [43, 139], decellularized tissue 
that contains collagen) or natural fibrin [140]. No contractility has been demonstrated with natural polymers, such as polysaccharide (alginate, chitosan, hyaluronic acid) or with synthetic polymers, such as PGA, PLA, PLC and polyurethanes poly(glycerol sebacate) (PGS), even if they are associated with collagen [141]. The self-assembling peptide technology with "RAD" failed to demonstrate the capability of obtaining a preparation with contractile properties in vitro and in vivo. Using this same technology (RAD), neonatal rat cardiomyocytes also have a low survival rate following implantation [142].

Contractility was initially evaluated with animal neonatal rat cardiomyocytes before the recent development of cardiomyocytes derived from human embryonic cells. Again, as in earlier experiments with animal cells, optimal contractility in vitro and in vivo is obtained for tissue containing several cardiac cell types: $65 \%$ cardiomyocytes, $25 \%$ fibroblast, and $5 \%$ endothelial cells. Most methods (electrical stimulation, mechanical stimulation, bioreactors and 3D scaffold (polymers used or a combination of polymers), method of production, orientation, nanotopography [130]) developed for neonatal rat cardiomyocytes [143] have been shown to work for human-derived cardiomyocytes in promoting embryonic cardiomyocyte survival and maturation. The contractile tissues with human cells were shown to also have engraftment following heart epicardial implantation [16, 144-148]. In vitro, cells require a 3D environment with a stiffness of around $10 \mathrm{kPa}$ to achieve terminal maturation of the contractile apparatus [79, 90]. More recently, it has been shown that beside stiffness [129], viscoelasticity also controls the differential potential of stem cells [75]. Collagen microarchitecture, such as the presence of micro fibrillar architecture, has been shown to be an independent factor in promoting the differentiation of contractile cells [78]. While the collagen as a natural structural protein has a natural viscoelastic component, this is not the case for most other polymers. The collagen, as a natural polymer, is the main component that determines the viscoelasticity of the heart myocardium [75]. Crosslinking of the 3D scaffold is associated with a decrease in this viscoelastic component [75].

\subsection{No contractility in 3D polysaccharide scaffold such as alginate or chitosan, even with RGD peptide}

Polysaccharides are molecules that display high biocompatibility and biodegradability. Most natural polysaccharides present groups such as hydroxyl, carboxyl and amino groups, which easily enable their chemical modifications. Alginate is one of the most studied natural polymers investigated for cardiac tissue engineering but no contractility has been demonstrated 
for it so far. Alginates have two main limitations: the absence of adhesion molecules and the low capability for spontaneous protein absorption. The use of alginates in association with collagen as composite microbeads encapsulating neonatal rat cardiomyocyte cells has been developed recently. The composite promotes the proliferation of cardiac cells, the formation of interconnected multilayer heart-like tissues, the presence of well-organized and dense cell structures, and spontaneous synchronized beating, but again there has been no true contractility demonstrated.

\subsubsection{No contractility in soft hydrogel of alginate, even with the RGD peptide (for review} [149])

In vitro, the $2 \mathrm{D}$ culture of neonatal rat cardiomyocytes on alginate hydrogel, even functionalized with the RGD peptide, has failed to support full differentiation of neonatal rat cardiomyocytes. The alginate hydrogels have a very low porosity of well below $1 \mu \mathrm{m}$, while optimal porosity is more than $30 \mu \mathrm{m}$ for angiogenesis in vivo. No differentiation of fibroblast towards myofibroblasts has been reported in the support, even in the presence of RGD and at a stiffness of $1 \mathrm{kPa}$, which is normally optimal for differentiation towards myofibroblasts. In vivo, in the model of acute MI, the association of RGD with alginate has even been reported as being deleterious and the functional benefits on ventricular remodeling as being lost. An explanation put forward by the authors is that after functionalization of the alginate with RGD, there is a 4- to 7-fold increase in stiffness. In our study, we have not found any modification of collagen after functionalization with Sulfo-LC-SPDP and RGD [44-46].

\subsubsection{In a solid porous alginate scaffold, functionalization with RGD increased contractile differentiation but there was no contractility}

Solid microporous alginate sponge scaffolds, with a low stiffness of around $1 \mathrm{kPa}$, were obtained by classical DE hydrothermal treatment (DHT) [150]. In these scaffolds, it was shown that the presence of RGD is essential for the survival and maturation of neonatal rat cardiomyocytes, which also involves stimulation of Akt signaling. However, no contractility was demonstrated in any of the experiments [150]. A combined effect was seen between RGD and heparin binding [150]. RGD increases $\alpha$-SMA and inter-cardiomyocytes connexin 43. In another study, the functionalization of a solid porous alginate, obtained by DHT with RGD, was shown to improve the differentiation of neonatal rat cardiomyocytes in vitro with an 
increase of connexin 43. The RGD also improved the capacity of non-muscle cells to have a contractile phenotype with $\alpha$-SMA expression and an increased collagen synthesis [151].

\subsubsection{Use of alginate 3D scaffold for non-contractile paracrine MSC delivery after MI}

Alginate hydrogel or solid patches have been shown to improve early human MSC retention. In acute rat MI, after intramyocardial injection of free human MSCs, only $10 \%$ of MSCs were present after 24h. Associating cells with injectable alginate or chitosan increases the retention by $14 \mathrm{x}$, and by around 50x if the cells are applied in a patch of porous alginate or solid DHT collagen onto the ventricle. However, over a longer time period, alginate hydrogel did not increase the cell retention rate anymore, which was only $7 \%$ after 2 weeks.

A solid porous composite scaffold of alginate and chitosan without RGD (obtained by DHT) was also developed, with a stiffness of $20 \mathrm{kPa}$. Applied to the infarct area immediately after MI with human MSCs, the preparation improved EF (ejection fraction) at/up to 1 month and decreased local fibrosis and angiogenesis.

\subsection{Best contractility achieved in natural polymers such as collagen/gelatin, fibrin or Matrigel}

In 2D culture, human cardiomyocyte cell lines (i.e. HL-1) have a better expression of inter cardiomyocytes connexin 43 on gelatin (that has a functionalized RGD site) or on gelatin with fibronectin, than on collagen type I. Laminin did not induce connexin 43. In vitro, maturation of human hiPSC in cardiomyocytes (hiPSC-CM) in a 3D environment is enhanced compared to that obtained in a 2D environment with polydimethylsiloxane (PDMS, Dow Corning) molds, fibrinogen and Matrigel ${ }^{\mathrm{TM}}[152]$.

\subsubsection{Contractility in gelatin hydrogel associated with fibrin or PMDS and neonatal rat cardiomyocytes}

In vitro, gelatin has recently been used as $3 \mathrm{D}$ hydrogel to engineer a true contractile tissue using 3D bioprinting technology with neonatal rat cardiomyocytes associated with fibrin and hyaluronic acid [136] or with poly(ethylene-glycerol-polydimethylsiloxane) (PMDS) [137]. Research has demonstrated the possibility, in vitro, of using the promising 3D printing technology to engineer a hydrogel with neonatal rat cardiomyocytes with gelatin. Preparations containing gelatin, in association with fibrin and hyaluronic acid, developed a force of $2 \mathrm{mN}$, and still with a low scaffold thickness value (i.e. $0.6 \mathrm{~mm}$ ) [136]. 


\subsubsection{Contractility in $3 \mathrm{D}$ gels of collagen, fibrin or Matrigel with neonatal rat cardiomyocytes or human cells}

Up to now, the best contractility has been obtained with thin strips of neonatal rat cardiomyocytes in collagen type I gels and cells embedded in a gel of tumor basement membrane (i.e. Matrigel ${ }^{\mathrm{TM}}$ ) and using chronic physical stimulus (mechanical or electrical stimulation) and high horse serum. However, the use of Matrigel ${ }^{\mathrm{TM}}$ has serious limitations since, as a gel, it will fill the pores of the scaffolds and modify cell interaction with the collagen scaffold. The Matrigel will also disturb nutriment diffusion, so that the use of a bioreactor is mandatory, which directly reduces the maximum thickness of the construct. In vivo, the Matrigel $^{\mathrm{TM}}$ is very immunogenic and the animal needs to be under immunosuppression. More recently it has been shown that the use of Matrigel ${ }^{\mathrm{TM}}$ could be replaced by thyroid hormone T3 at the beginning of the protocol [153]. The authors report the development of a force of around $78 \mathrm{mN} / \mathrm{nm} 2$ [154] or $2 \mathrm{mN}$ [155]. The exact role of T3 needs to be evaluate but an RGD binding site on the T3 thyroglobulin has been shown to interact with $\alpha v \beta 3$ and $\alpha v \beta 5$ in tumor cells. Thyroid hormones have been shown to increase contractility. T3 promotes the maturation of hiPSC-derived cardiomyocytes.

More recently, in fibrin or collagen gels, contractile tissues have been developed with human cardiomyocytes derived from embryonic cells (ES or hiPSC) (for reviews[156]) . Contractility has been demonstrated in collagen type I gels or fibrin gels seeded with human contractile cells. Protocols for the differentiation of cardiomyocytes or myofibroblasts derived from human embryonic stem cells have been documented. In one study, the derived cells were incorporated into collagen type I gel and then underwent mechanical and electrical stimulation. Unlike for neonatal rat protocols, the use of Matrigel ${ }^{\mathrm{TM}}$, T3 or insulin is not necessary. The addition of laminin or fibrin does not improve contractility. Optimal contractility has been observed for a preparation with $70 \%$ of cardiomyocytes and $30 \%$ of fibroblasts. It is possible to engineer a construct with a thickness of up to $0.5 \mathrm{~mm}$ and a large size of $35 \times 34 \mathrm{~mm}$. These constructs contain $40 \times 10^{6}$ cardiomyocytes and develop forces of $1.5 \mathrm{mN}$ under optimal conditions at 6 weeks [147]. In another study, collagen type I gel with human induced cardiomyocytes was transferred onto a stretcher for functional mechanical maturation for an additional 12-14 days. If T3 and insulin are used for at least $24 \mathrm{~h}$ after the casting, the use of Matrigel $^{\mathrm{TM}}$ is not necessary. The stretching allows terminal cardiomyocyte maturation of the contractile apparatus with an average force of $0.35 \mathrm{mN}$ by loop. The construct was able to be transported for 2-3 days at $21^{\circ} \mathrm{C}$ and then implanted in a rat model of chronic infarct heart (1- 
month old). In the first few days there is a rapid alteration of cellular viability with less than $20 \%$ of long-term surviving cells. The preparation improves the ventricular remodeling but not the contractility. The effect is independent of cell survival, suggesting again a paracrine effect [146].

Contractility has also been demonstrated in 3D fibrin gels seeded with human contractile cells. Patches with human hESC were developed in fibrin gel in vitro with a better contractility for mixed preparations of cells derived from hESC with 70-80\% of cardiomyocytes (hESC-CM). These preparations with fibrin gels survived and became electrically incorporated after transplantation onto a large swine infarct. The presence of a cellularized patch decreased the infarct size and increased neoangiogenesis in the peri-infarct region [12].

Moreover, the fibrin gel was associated with a synthetic polydimethylsiloxane (PDMS) polymer to control the 3D microarchitecture. Maturation of hiPSC-CM is obtained if the structures are electrically stimulated, but no true contractility has been demonstrated [145]. The survival and electrical incorporation of a thin epicardial patch of human hiPSC-CM in a construct of PDM, fibrinogen and Matrigel ${ }^{\mathrm{TM}}$ has been demonstrated in nude mice [144].

\subsubsection{Interesting long-term contractility and thick tissue obtained in vitro in solid porous collagen scaffolds}

The most advanced 3D constructs in terms of tissue structure and long-term functioning have been obtained with neonatal rat cardiomyocytes seeded in solid collagen sponges, with chronic electrical pacing and Matrige ${ }^{\mathrm{TM}}$ with the mandatory use of bioreactors $[31,33]$. A classical easy way to obtain a solid collagen scaffold is to use a physical de-hydrothermal type of production that allows a mild physical reticulation of the scaffold at the same time. Highly porous collagen sponges with a pore size of 20-200 micrometers allow free nutriment diffusion [40]. During the process of DHT it is also possible to create a temperature gradient to obtain an oriented collagen scaffold that promotes the maturation of contractile cells. The electrical mapping of the solid DHT collagen has been investigated with homogenous conductibility [157]. Radisic M. et al. have demonstrated how a 3D collagen non-oriented porous scaffold, used as a clinical hemostatic, can be used for tissue engineering of a contractile tissue when seeded with neonatal rat cardiomyocytes [31]. For cell seeding, a gel (Matrigel ${ }^{\mathrm{TM}}$ ) was necessary. The use of Matrigel inside the scaffold limits nutriment diffusion and a perfusion bioreactor was therefore necessary. For cellular maturation, the use of chronic electrical stimulations was also necessary. In the Radisic experiments in neonatal rat cardiomyocytes, the 
stimulation threshold was around $3 \mathrm{~V} / \mathrm{cm}$ [31]. We performed the same experiment with the same solid DHT collagen scaffold functionalized with RGD, and without the use of Matrigel, bioreactors or chronic electrostimulation, and we were able to engineer a contractile patch with a lower threshold of around $1 \mathrm{~V} / \mathrm{cm}$ [38]. This last stimulation threshold is within the range of the natural stimulation threshold in the heart. With the mouse myoblast cell line $\mathrm{C} 12 \mathrm{C} 12$, it has been shown that electrical stimulation induces contractile apparatus maturation in this solid collagen DHT [158]. In the same solid porous collagen scaffold, obtained by DHT seeded with neonatal rat cardiomyocytes, we have demonstrated that Matrigel ${ }^{\mathrm{TM}}$ is not necessary. Collagen functionality can be improved by chemical functionalization with the key RGD peptide that is not functional on natural collagen [38]. In the scaffold functionalized with RGD and without Matrigel, perfusion and electrical stimulation, we reported a contractility of $90 \mu \mathrm{N}$ with RGD, and around $30 \mu \mathrm{N}$ without it [38]. In addition, the stimulation threshold for the RGD collagen preparation is very low, below $1 \mathrm{~V} / \mathrm{cm}$ for $\mathrm{RGD}$, and around $3 \mathrm{~V} / \mathrm{cm}$ without it [38]. We could engineer a contractile patch with a thickness of several $\mathrm{mm}$. We have reported the very high porosity and low compliance of a collagen patch of around $1 \mathrm{kPa}[40,44]$ that is not modified by functionalization with the RGD peptide, thanks to the peptide functionalization method that we developed [44-46].

For optimal cardiac tissue, it is important that the scaffold promotes the survival and differentiation of other cardiac cell types, such as endothelial cells and MSCs. Our research [44] and that of others [47] has observed that MSCs seeded in solid DHT collagen present increased paracrine and regenerative properties. We have also demonstrated, in vitro, how human MSCs seeded in a RGD collagen scaffold in the presence of a classical culture medium for expansion (rich in plated lysate containing TGF $\beta$ ), massively differentiate towards contractile myofibroblasts [44-46]. The functionality in terms of paracrine activity is stronger than in 2D cultures and is not altered during differentiation [44]. We have also reported how solid collagen RGD scaffolds promote the differentiation of human cardiac cells ("e.g. cardiospheres") towards cardiomyocytes [40]. Moreover, the RGD scaffolds, compared with collagen, enhance the differentiation of mouse embryonic stem cells (EBS 5 days) towards cardiomyocytes if seeded in collagen RGD [159]. The development of angiogenesis is essential for tissue engineering and survival following implantation, and also for optimal contractility in vitro. A functionalization of the DHT scaffold with VEGF and/or angiopoietin 1, has been proposed by Radisic M. et al. Again, growth factors need to be covalently bound to the collagen scaffold for efficiency. The RGD is crucial for interaction with endothelial progenitor cells at 
vasculature sprouts during angiogenesis. The solid collagen DHT scaffold has been used to replace the entire thickness of rat right ventricle for up to more than one month [160]. The functionalization of collagen patches with VEGF induces higher neoangiogenesis and maintains patch thickness [160].

Our group was the first to demonstrate in mice [28] and in humans [29, 30] that a solid porous collagen scaffold, cellularized with human bone marrow and applied to recent chronic infarcts in association with an intramyocardial injection, obtains more satisfactory results than free intramyocardial cell injections alone.

\subsection{Contractility with decellularized tissue For review [161,162]}

\subsubsection{Classical methods for obtaining a decellularized matrix tissue and its limits}

The decellularizing process is obtained by chemical (SDS detergent-based method), enzymatic (Triton $\mathrm{X}-100$ ) or physical treatment of the tissue to remove the cells while preserving most ECM components and organization as far as possible [162]. It has been shown that each organ-specific ECM promotes maturation of specific progenitors and then the natural cardiac extracellular matrix is the most promising matrix for cardiac cells [162]. Important limitations of decellularized ECM are their low porosity, limiting cellular colonization and nutriment diffusion, and their ability to preserve native ECM component stoichiometry, such as basal lamina versus structural protein fractions. Reproducibility between different donor hearts remains a significant challenge, as does the higher immunogenicity of these matrices compared to that of reconstituted collagen [162].

In an effort to improve the mechanical properties of decellularized ECM-based products, a composite scaffold of soluble decellularized ECM with chitosan and alginate was recently examined and was found to enhance human MSC proliferation, but no contractility was demonstrated. Crosslinking of decellularized ECM with a chemical reagent (i.e. genipin) was shown to impair cell matrix interaction with decreased $\alpha 5$ and $\beta 1$ in associated MSCs. Also observed was a tendency for bone differentiation.

\subsubsection{True contractility demonstrated only on thin sections of decellularized tissue}

3D decellularized extracellular matrix preparations have been shown to be superior to 2D preparations for cardiac differentiation [163]. In 3D constructs, differentiation of iPSCderived cardiomyocytes is enhanced with an increased beating activity. However, no true 
contractility has been demonstrated [163]. A thin section $(150 \mu \mathrm{m})$ of decellularized heart matrix was seeded with human-derived cardiomyocytes from hESC-CM or hiPSC-CM for 3 weeks. Homogenous cellular colonization of the full scaffold thickness was observed. Peak twitch stress was measured at $0.49 \mathrm{mN} / \mathrm{mm} 2$, but with a low thickness value. While some progress with human ECM-based scaffolds has been made [164], the contractility of the resulting fECTs is very low, with generated forces in decellularized scaffolds and whole hearts amounting to only $100 \mu \mathrm{N}$ [164].

\section{Possible engineering of a large contractile patch with human cells (hESC-CM) in gels of Matrigel, fibrin or collagen (for review [16])}

Recently, a patch with hESC-CM was implanted in a chronic infarct heart in macaque. The scaffold used was a Matrigel ${ }^{\mathrm{TM}}$ gel. The preparations were mechanically stimulated for 1214 days before implantation. In immunosuppressed macaque, the preparations survived for more than 220 days with a well-organized mature sarcomere alignment. A limitation was the presence of ventricular arrhythmias in $100 \%$ of the animals. In vivo, further maturation of hESC-CM was reported along with electrical coupling between native macaque

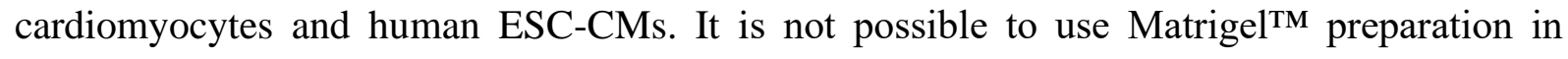
humans [148]. Optimizing the stimulation threshold of the preparation may decrease the prevalence of arrhythmia.

In another study, a fibrin gel was used with different types of human cells derived from ESC (embryonic stem cells) and resulted in the development of ESC-CM (cardiomyocytes), endothelial cells and smooth muscle cells. The preparations were mechanically stimulated in vitro. Patches up to $1.25 \mathrm{~mm}$ in thickness were developed for a period of 7 days before implantation. Stability of the preparations for a longer period was not evaluated but gels are known to present very poor mechanical properties. The patches were implanted onto the MI zone very early after MI (60 min.). No arrhythmia was reported with this composite patch. However, only $10 \%$ of the cells survived in the patch. Nevertheless, the patch still improved left ventricle contractility, mostly by a paracrine activity in the border zone [12]. Cardiopatches of hiES-CM have been developed in collagen gel type I with mechanical stimulation for 12-14 days. The preparation could be shipped at ambient temperature and applied to the left ventricle in models of chronic heart ischemia. $25 \%$ of the cells in the patch survived for a long period of 220 days [146]. 


\section{Rationale for using collagen or gelatin as a polymer backbone for tissue engineering 3D scaffolds and the limits of hydrogels and gels}

\subsection{Rationale for using collagen type I or III as a polymer backbone}

Collagen is the major constituent and structural component of the ECM including the cardiac extracellular matrix and is therefore an obvious choice as a scaffold material for regenerative medicine. Collagen monomers have a natural propensity for spontaneous fibrillogenesis and for forming porous 3D structures. Collagen provides a biomimetic environment for cell growth, since it has a fibrous structure, appropriate mechanical properties (stiffness/viscoelasticity and resistance to deformation) and some important adhesion molecules. In addition, it is highly biocompatible and biodegradable.

The cardiac ECM is composed of structural collagen type I (80\%), collagen type III $(10 \%)$ and non-structural proteins $(10 \%)$, such as collagen IV, laminin, or fibronectin. Collagen I fibrils provide the majority of the tensile strength, while the addition of collagen III to collagen I is found to increase tissue elasticity [165][170]. Collagen type III is very flexible compared to collagen type I [166] and is the main collagen component surrounding the cardiomyocytes. Fibronectin, containing a RGD motif that is critical in its functionality, is ubiquitously present in the ECM of normal myocardium and surrounds the cardiomyocytes [166]. Laminin has been shown to be secreted on collagen by cardiomyocytes and to directly control the initial sarcomere $\mathrm{Z}$ band organization and development [36]. The fibronectin has the same distribution as laminin in the ECM and probably reinforces the maturation of the contractile apparatus.

\subsection{Limits of gelatin as a natural polymer backbone}

Gelatin is a thermally denaturized collagen and possesses a more disorganized structure than normal collagen, which considerably alters material mechanical stability. Denaturation alters the macromolecular order in collagen but the chemical composition is largely maintained. With gelatin, the tendency of natural collagen to spontaneous fibrillogensis is lost and engineered scaffolds have a reduced porosity. At the same time, in random gelatin the important binding site "RGD" is available, while it is not functional in native collagen [167].

The possible use of different amounts of several components such as collagen, gelatin and elastin to design soft material has been investigated in the presence of fibrosarcoma cell lines. To maintain large pore size for cellular colonization, chemical crosslinking by carbodiimide is necessary to maintain structural stability, strength and resistance to degradation 
in all the scaffold preparations mentioned above [41]. In vivo, the results with gelatin-based scaffolds are very poor when compared to collagen-based scaffolds. There is an early, very extensive infiltration of the biomaterial after implantation in the muscle. The quantity of angiogenesis in the gelatin is increased for up to one month. But then, there is a fibrotic scar with poor very angiogenesis [167]. That is not the case in native collagen biomaterials [167].

\subsection{Structural limits of collagen or gelatin hydrogels and gels for contractile tissue engineering and the necessity for reinforcement by reticulation or association with structural polymers}

\subsubsection{Limits of contractility reported in hydrogels of gelatin or collagen}

Collagen type I scaffolds have several limitations when used as hydrogel for cardiac tissue engineering for the following reasons: 1) they are not easily remodeled to yield physiological cell density and connectivity; 2) they do not stimulate endogenous matrix secretion by cardiac cells; and 3) they are stiffer than other hydrogel scaffolds. As a result, collagen I does not provide ideal conditions for cardiomyocyte maturation and macroscopic contractions. Furthermore, collagen I hydrogels have a long gelling time which can lead to a settling of seeded cells during polymerization, yielding a non-uniform cell density.

Gelatin hydrogels have poorer structural properties than collagen hydrogel and thus need to be reinforced. Specifically, gelatin methacrylol (GelMA) hydrogels have tunable biophysical and biochemical properties and have been increasingly used for the generation of contractile cardiac tissue. However, the functional properties of cardiomyocytes embedded in GelMA hydrogels remain inferior to those in collagen I and fibrin-based tissues. In hydrogel of gelatin-PEG, the 3D structure has revealed an over-expression of $\beta 1$ integrins on human cardiac stem cells and optimal differentiation for $8 \mathrm{kPa}$, not $2 \mathrm{kPa}$.

\subsubsection{Limits of contractility reported in gels of gelatin or collagen}

The main limits of collagen gel are its limited stiffness, poor mechanical quality and a low porosity that is not optimal for nutriment diffusion. In addition, the mechanical properties of the gel rapidly degrade in vitro. If not functionalized with the RGD peptide, collagen type I may therefore not be an ideal polymer, due to the lack of functional RGD sites. When coated on collagen type $\mathrm{I}$ in 2D cultures, the collagen failed to induce IES differentiation towards cardiomyocytes. In 3D collagen gel type I, different stiffnesses were tried [168] but the contractility of neonatal rat cardiomyocytes was impaired for all the stiffness level [169]. 
In $2 \mathrm{D}$ and $3 \mathrm{D}$ constructs, human myoblasts have been shown to interact with the RGD motif ( $\alpha \mathrm{v} \beta 3$ and $\alpha 15 \beta 1)$ in gelatin, but not in collagen [139]. Denaturation of collagen to gelatin is accompanied by the loss of collagen receptor GxOGER and the appearance of the cryptic RGD. It has been suggested that associating a certain proportion of gelatin and collagen might improve the biofunctionality of the preparation. In mixtures of gel of collagen with gelatin, a decreased availability of GxOGER has been observed, along with an increased availability of RGD [139]. Not surprisingly, the association has a significant effect on the scaffolds' mechanical properties, which become considerably inferior to scaffolds made with collagen only and, therefore, more unpredictable [139].

Several techniques have been developed to improve gel physical properties, chemical reticulation, and association with other synthetic or natural polymer components. The limits of collagen's chemical reticulation have been shown with the alteration of its biological functionality by a significant disturbance of the recognition motif for integrins and further limitations of gel porosity. In addition, the fibrillar network that improves interaction with associated cells is not spontaneously present in collagen gel [78]. Compared with a scaffold of just collagen, the addition of gelatin reduces both scaffold stiffness and degradation time. The reticulation of the entire scaffold is essential for structural stability, strength, and resistance to degradation [41]. The chemical reticulation of the scaffold is performed with a chemical reticulating agent EDC. The stiffness of the scaffold of just collagen is too high (around $80 \mathrm{kPa}$ ) as opposed to around $4.6 \mathrm{kPa}$ for gelatin alone [41]. Chemical reticulation of gelatin and collagen with EDC has been shown, in 2D and 3D, to alter the RGD and GxOGER receptor sites in gelatin and collagen [139]. It has also been shown that after chemical reticulation of collagen type I with EDC, it is possible to partially recover the functionality by further functionalization of the collagen with the collagen receptor (i.e. GFOGER) [43].

Long-term maintenance of myofibrobasts in collagen gel has been shown to require the gel being attached and thus being stretched. In our in vitro study of a solid collagen scaffold with low stiffness, we were able to induce and maintain myofibroblasts from human MSCs for several weeks, without the need for stretching the scaffolds [44]. Recently, collagen type I gels not functionalized with the RGD but in association with Matrigel ${ }^{\mathrm{TM}}$ have been shown capable of sustaining human hESC-CM maturation in vitro. The presence of MSCs, fibroblasts and mechanical stress improves the contractile maturation of the preparation. In this experiment, stress was shown to increase in the integrins for the RGD motif $\beta 1, \alpha \mathrm{v}$ and $\alpha 5$ [170]. 


\section{Rationale for having a solid 3D scaffold obtained by physical reticulation instead of chemical reticulation}

In the tissue, the cell regulates the ECM by intrinsic crosslinking (transglutaminase) or by interacting with several multivalent proteins that reinforce the tissue. In vitro, however, physical properties of reconstituted collagen can be improved by crosslinking: physical crosslinking, chemical or enzymatic. Reticulation is a way of improving material stiffness, in hydrogels or gel for example, to limit material degradation and to maintain material 3D structural properties, such as porosity and orientation, and ultrastructural properties. But reticulation also decreases scaffold viscoelasticity.

A common form of reticulation is chemical reticulation, in which the agent used should be not cytotoxic initially or at the time of degradation. However, most chemical reagents are cytotoxic, although some have a lower toxicity, such as EDC/NHS or genipin. Collagen product crosslinking by chemical reagents most often occurs on a free $-\mathrm{NH} 2$ amine group present on the collagen. These sites are limited and are also used for collagen functionalization with adhesion molecules. A crosslinking step is often use to stabilize the mechanical and degradation properties of materials but has a major drawback in its detrimental effect on cell biology. Chemical crosslinking of collagen film with EDC/NHS to modify substrate stiffness is accompanied by a loss of reactivity towards the important collagen-binding GFOGER motif for $\alpha 1 \beta 1$ and $\alpha 2 \beta 1$ [70]. Functionalization of collagen films with the GFOGER restores collagen functionality after EDC/NHS reticulation [42, 43].

During the fabrication of 3D collagen scaffolds, such as DHT scaffold (Dehydrothermal treatment), a mild physical reticulation occurs at high temperatures. For the purpose of tissue engineering, we believe that the use of mild physical reticulation is superior to chemical reticulation because it preserves most of the biological properties of the polymer. In addition, many chemical reticulating agents are toxic for the cells. At the same time, we have reported the possibility of using a physical rather than chemical reticulation of collagen to obtain a solid scaffold still with a with low stiffness (around $1 \mathrm{kPa}$ ) [44-46]. In this scaffold, we [38] and others [31] have demonstrated the possibility of forming a very efficient contractile constructs in the presence of neonatal rat cardiomyocytes. We also compared, in vitro, the differentiation capability of "human cardiospheres" seeded in 3D gelatin scaffold (i.e. "foam") crosslinks with EDC to improve mechanical properties or in 3D collagen type I/III scaffolds, obtained by DHT and thus with a mild physical reticulation. While the stiffness of both scaffolds was low and the 
same (i.e. around $1 \mathrm{kPa}$ ), the differentiation of human cardiospheres towards cardiomyocytes was 3 times higher in the RGD scaffold than in gelatin, and the expression of $\mathrm{Cx} 43$ intercardiomyocytes junctional proteins was enhanced [40]. After seeding human "cardiosphere clusters" in the different collagen RGD or gelatin solid scaffolds, the cluster stays intact in the gelatin-based scaffold while in collagen RGD the cluster organization disappears and the cell migrates, resulting in an equal distribution of cells throughout the scaffold [40]. Collagen RGD may be more appropriate for inducing cardiosphere cardiac differentiation and for engineering a contractile tissue [40]. Again, the additional chemical reticulation of solid DHT scaffold made of collagen and chondroitin by chemical reagent EDC is again associated with important changes in the 3D architecture [171].

\section{Functionalization of biomaterials with peptides such as RGD $[48,50,133]$}

The different ways for functionalization of synthetic materials that have been used for cardiac tissue engineering has been reviewed [133]. Numerous materials have been functionalized with the RGD [172]. There are two strategies for the biofunctionalization of polymers. The first is pre-polymerization functionalization via polymerization of functional monomers (e.g. alcohols, carboxylic acids, amines, and acrylates). This procedure provides, for example, functional polyesters or polyurethanes with a defined chemical structure that allows further modifications following polymerization. The second strategy is a post-polymerization functionalization, which is the modification of the polymer after the polymerization process. Post-polymerization techniques might be specific, targeting functional groups present in the polymer via carbodiimide or UV-initiated radical coupling, or non-specific, using azide- or glutaraldehyde-based coupling. A disadvantage of the non-specific covalent functionalization method is that it may result in the destruction of biomolecule bioactivity and/or can involve side reactions such as hydrolysis, chain-degradation, or cross-linking. Different techniques for the addition of RGD peptide during scaffold fabrication, such as electrospinning or 3D printing, have been documented [50].

While the functionalization of synthetic polymers that lack all adhesion molecules is logical, it appears that in natural polymers, the associated cells often secrete their own membrane basal ECM protein, so that functionalization is not always necessary. Neonatal rat cardiomyocytes on natural collagen type I have been shown to synthetize their own basement membrane of laminin [36] and, in a more recent study, adult rat cardiomyocytes in vitro have been shown to synthetize collagen type VI and laminin [36]. In many cases, the 
functionalization of scaffolds with oligopeptides corresponding to the binding site of integrin receptors, can recapitulate the full protein activity [67][76]. The main proteins of the ECM are collagen, vitronectin, fibronectin, laminin, and collagen type I. All these proteins, in terms of biological signaling, can be replaced by short peptides (namely RGD for vitronectin and fibronectin), IKVAV and YIGSR for laminin, and GFOGER for the collagen.

The mere absorption of the ligands on the surface leads to unpredictable, nonspecific and potentially unstable interactions with both the cell and the material surface. For correct integrin activation and clustering, the cell needs to provoke a traction force on the ligand and, if the ligand is not fixed to the ECM, the correct activation does not occur. High forces are exerted on the interface and this enhances cell interactions with the formation of integrin receptor clustering and focal adhesion complexes (FAK). The absence of covalent fixation and possible peptide internalization has a deleterious effect on the cells. Much better results are obtained with chemical linkers. The interactions between cells and materials is based on several parameters, among which the densities of integrin binding ligands, anchorage and presentation on the surface are indispensable factors. For optimal efficiency, RGD should be bound and present a spacer arm of around 30-40 Angstroms [172]. For optimal interaction with human MSCs in poly(ethylene glycol) (PEG) hydrogel, it has been shown that the RGD should be covalently bound. However, the soluble RGD has the opposite effect. The RGD bonded to this last hydrogel increases the expression of $\alpha v \beta 3$ in associated MSCs to $90 \%$ positive while only $10 \%$ are positive in the absence of RGD. Maximum interpeptide distance has been shown to be $50 \mathrm{~nm}$. However, this can increase up to $200 \mathrm{~nm}$ depending on substrate rigidity. In 2D, the minimum distance only influences the bioactivity in regular patterns. Optimal density in 2D is $50 \mathrm{pmol} / \mathrm{cm}^{2}$. A branched peptide enhances the bioactivity by promoting integrin clustering.

\section{Functionalization of solid collagen with the RGD peptide}

Modifying strategies to target a uniquely reactive amino acid can be a particularly powerful step. There are several strategies for the coupling or conjugation of biomaterials with oligopeptides, including chemical modification, enzyme mediate conjugation, photo conjugation and activation, photocaging and the activation of reactive functionality [134].

Methods for the functionalization of scaffolds with the RGD peptide has been reviewed [172]. Glycosaminoglycan collagen matrices have been shown to be enhanced by RGD derivatization [171]. For collagen, functionalization mostly occurs on the $-\mathrm{NH} 2$ sites present on lysine, glutamate and aspartate amino acids. The number of amine sites is limited. We have 
developed a very safe method for collagen functionalization with GRGDS peptide in 3D porous solid scaffolds by means of heterogeneous solid phase synthesis and an optimal presentation by introducing a 36-angstrom spacer. The stiffness of the scaffold is not modified by functionalization with the RGD peptide [44, 45]. Although the substitution of biomaterial is supposed to be simple, the functionalization of alginate, which is a classical type of scaffold for cardiac tissue engineering, with the RGD peptide results in a total loss of its bioactivity due to a 4- to 6-fold increase in stiffness [173].

The peptide is unidirectional substituted on a free $-\mathrm{NH} 2$ site present on collagen. The water-soluble Sulfo-LC-SPDP is used to modify the -NH2 site on the collagen and on the NH2 site on the glycine of the GRGDS peptide. The derived collagen is reduced, separately washed, and then reacts with the other reagent [38]. An amide bond is formed. During the final step of the modification process, a thiol group is liberated in the medium that can be measured for monitoring and quantifying the covalent fixation. We have also demonstrated the introduction of a flexible spacer arm of 36 angstrom, which has been shown to be optimal for RGD peptide presentation [38].

More recently, we have demonstrated how this scaffold, functionalized with the RGD, can be used for the differentiation of mouse embryonic cells towards cardiomyocytes [159], the differentiation of human cardiospheres towards cardiomyocytes [40] and the differentiation of human MSCs towards contractile myofibroblasts [44-46]. We have also shown, in vitro, how functionalization with the RGD peptide improved contractility by improving actin/myosin cross bridges in human myofibroblasts derived from hMSCs [46]. Because of their paracrine functionality, MSCs are important cells for delivery after MI. We have also found that human MSCs in this solid collagen DHT scaffold, with or without RGD, preserve their paracrine function and their immunosuppressive capability that is even enhanced as compared with classical two-day cultures [44]. Human MSC in the collagen DHT has also been recently assessed by the research group of Radisic M. et al. [47].

\section{Positive effects of RGD on most biomaterials for limiting MI size and for cell therapy in the heart}

Limited success in cell therapy is possibly due to poor initial cellular retention and survival in hypoxic and inflammatory environments. The application of cells through a patch in contact with the epicardial layer, and not in the infarct zone, may be a way of optimizing the treatment of the epicardial layer and border zone where generation takes place. It has been shown in large 
animal models of ischemia that epicardial cell application is better than intramyocardial injection in treating the epicardial layer [174]. The association of the cells with 3D scaffolds functionalized with the RGD may be a way of improving cell retention and survival [17].

Due to their paracrine functionality and safety, MSCs are one of the most promising cell groups for cell therapy in the heart. The transplantation of MSCs in collagen patches or in decellularized tissue applied onto the contractile muscle has failed to prevent cell migration. In peripheral muscular tissue, or in a beating heart, almost $90 \%$ of the cells are lost after 1 or 2 days [175]. Cell death limits initial retention and secondary migration. After implantation of MSCs in a decellularized tissue and its application onto the infarct area, there is a 50\% secondary migration of MSCs at 8 days [176]. In non-beating peripheral muscle, after administration in mice of MSCs in collagen 1 gel, Matrigel ${ }^{\mathrm{TM}}$ or decellularized tissue (i.e. Purametrix), there is less than $10 \%$ cellular retention of MSCs after 1 month. The same results were found after implantation of rat cardiomyoblasts onto the MI area in a heterotopic heart transplantation model [177]. The functionalization of the scaffold with RGD may be a way to improve cellular retention. The presence of RGD in a nanofiber matrix has been shown to enhance mice bone marrow retention in ischemic limbs from 4 days to 1 month [178].

While free alginate scaffold has been found to improve remodeling after MI, this effect is lost after functionalization with the RGD peptide, due to increased scaffold thickness. The alginate functionalization with RGD induces a beneficial effect in vitro and in vivo in human endothelial cells. We believe that the functionalization of collagen with the RGD peptide, with or without cells, may be a way of providing these signals without the full protein.

\section{Possible use of an empty solid collagen sponge and application to an infarct area without a cellular component, but with growth factors or exosome}

The collagen sponge can be functionalized with the RGD peptide and associated with a biological non-cellular agent that recapitulates most cell paracrine functionalities.

\subsection{Possible use of a solid empty reconstituted collagen scaffold alone}

Many solid collagen sponges are in clinical use as hemostatic sponges. DHT sponges were applied onto the infarct area provoked by local cryoinjury in rats. After D60, there was a total elimination of collagen sponge and local angiogenesis in and under the patch in the infarct area [179]. There was also a trophic effect on granulose tissue. No contractile cells were observed in the patch [179]. The epicardial application of a collagen DHT patch has also been reported 
by another group in rats up to 6 weeks after MI, resulting also in a good integration of the scaffold, no foreign body reaction, neovascularization, and remodeling, but not still no improvement of the systolic function [180]. A DHT collagen patch, Ultrafoam ${ }^{\mathrm{TM}}$, was used to replace the full thickness of a rat right ventricle up to one month. There was a significant decrease in patch thickness. Modifications of the patch with VEGF, which also need to be covalently bound for functionality reasons [160], limited patch remodeling [160]. A collagen patch but chemically crosslinked by EDC was implanted onto infarct area in rat. There were very few cells infiltrating at 3 weeks and a foreign body response was observed at the periphery [181].

\subsection{Possible use of the collagen patch with growth factors or exosomes containing growth} factors

\subsubsection{Reconstituted solid DHT collagen associated with periostin}

After MI, matricelluar proteins play a key role by promoting tissue sparing, tissue regeneration and angiogenesis. In many cases, the RGD functionality is involved. A collagen patch was used for delivering the matricellular protein (i.e. periostin) that was not covalently bound and then epicardially applied 2 days after MI in a large (pig) animal model. The presence of periostin increased the EF from $31 \%$ to $41 \%$, decreased fibrosis by $22 \%$, and led to a decrease in MI size at 12 weeks [27]. Integrin $\alpha v$ FAK/Akt activation and the RGD site of periostin contribute to the beneficial effect on infarct area [182]. However, periostin was also associated with an increase fibrosis of none infarct remote myocardium [27].

\subsubsection{Association of solid collagen sponge Ultrafoam $^{\text {TM }}$ with VEGF or angiopoetin1}

The vascular endothelial growth factor, immobilized to a collagen scaffold, promotes penetration and proliferation of endothelial cells [183]. Research has shown how the growth factor needs to be covalently bound to the scaffolds for optimal functionality [183]. In vivo, the use of collagen, with or without the VEGF, was even used to replace the full thickness of the right ventricle. VEGF-treated patches are significantly thicker than controls, and thickness correlates positively with neovascularization. Importantly, angiogenesis in VEGF scaffolds has been shown to contribute to improved cell survival and tissue formation [160].

\subsubsection{Association of collagen patch with FSLT1 (follistatin -like1)}


A compressed collagen patch was used in conjunction with protein FSLT1 (follistatin like1) and applied to an infarct area 10 days after MI. FSLT1 is secreted by MSC. The application of FSTL1 via an epicardial patch stimulated cell cycle entry and the division of preexisting cardiomyocytes, and improved cardiac function and survival in mouse and swine models of myocardial infarction [26]. Only the application of collagen with the growth factor, and not the delivery of cells secreting the growth factor, was shown to be effective [26]. The compressed collagen type I has a very low porosity $(1 \mu \mathrm{m})$, which is particularly low for cellular colonization.

\subsubsection{Association of collagen patch with exosome}

As with other growth factors, collagen could be used for the local delivery of exosomes. The paracrine effect of transplanted cells is mediated in part by exosomes, nano-sized (less than 100-150nm diameter) regulatory vesicles that are secreted by most cells and contain a variety of proteins, RNAs and growth factors. In contrast to individual bioactive components, exosomes provide a unique method for the cells to deliver a package of bioactive components. Exosomes have been shown to enhance the proliferation, survival and angiogenic potential of cardiac cells in both small and large animal models. For example, exosomes of cardiospheres attenuate LV remodeling and improve cardiac function in swine models of acute MI.

\section{Possible use of a solid collagen scaffold for epicardial cell delivery in the context of MI}

In the context of MI, we have previously shown in mice [28] and humans [29, 30] how the delivery of bone marrow cells associated with a patch and epicardially applied, is superior to free intramyocardial cell injections. More recently, we seeded human cardiocell clusters in vitro in a collagen-DHT RGD scaffold or gelatin foam and showed how the presence of RGD enhances their cardiogenic potential. With regard to cardiosphere-derived cell retention, intramyocardial injection in hyaluronic-gelatin hydrogel increases cellular retention compared to that obtained with the classical clinical intracoronary administration. The effect of stem cell therapy has been found to be even better in animal models after the epicardial application of a sheet containing collagen IV and hyaluronic acid.

16. Current challenges for cellular therapy after MI and the possible use of collagen scaffolds functionalized with the RGD peptide for the delivery of paracrine human MSCs or human cardiopshere cells 
The clinical impact of cell-based therapy is limited by the low engraftment rate [9]. Most of the impact, including that for contractile cells, is due to the paracrine effect of transplanted cells. The delivery of an engineered cardiac tissue patch sutured onto the surface of the MI results in 10 times more engraftment than that resulting from free cell injection, even for paracrine cell delivery. The patch may provide a better environment for cell retention and survival in the context of MI. At the same time, while cardiomyocytes have a low propensity for migration outside the heart, after local administration in a patch, this is not the case for MSCs, as they already have 50\% migration outside the heart after only 4 days [176]. Thus, a specific strategy should be adopted. Cases of survival, angiogenesis and electrical coupling of cellularized patches after MI have been reported after epicardial applications.

There is growing evidence that the cells should be transplanted as soon as possible after MI, probably in the first 2 days. Having a preparation of cells that is already available in the center is challenging, since cryopreservation is the classical method of MSC preservation and MSCs require $48 \mathrm{~h}$ to recover their paracrine functionality (after DE freezing) and adhesion properties. This is still challenging in the context of MI. Immunological issues remain with hiES-CM and in relation to the scaffolds (collagen or decellularized tissue) or Matrigel ${ }^{\mathrm{TM}}$. Tissues obtained from gel have poor mechanical properties and solid scaffolds may be preferable to preserve 3D architecture, stiffness, porosity, and nutrition, and to improve the transfer and preparation of thick tissue. Endocardial cell injections are not optimal for treating the epicardial layer, where most post-MI cardiac regeneration takes place. We have shown in humans [29, 30], in the context of recent MI in patients requiring sternotomy for bypass operations, and in mice [28], that the association of bone marrow cells in a collagen hemostatic patch produces better results than free cell injections for controlling ventricular remodeling.

Increasing evidence suggests that the therapeutic benefits of MSCs following transplantation may largely be attributed to the paracrine and trophic function of these cells rather than their differential potential. In addition to their well-known multi-lineage potential, an intriguing characteristic of MSCs is their ability to secrete a wide range of bioactive cytokines that can influence nearby cells via paracrine signaling such as VEGF, FGF, HGF, IGF, PDGF, ILs and MMPs. MSC paracrine functionality is controlled by indolaleamine 2,3 dioxygenase 1 (IDO). The effects of 3D biomaterials on MSC differentiation are mostly unknown, as are the effects of MSC differentiation on their functionality. The paracrine capability of MSCs decreases after differentiation towards osteocytes in a 3D collagen scaffold. At the same time, 3D culture conditions such as cluster formation ("spheroid") increase MSC 
paracrine potential. Solid 3D DHT Collagen (i.e. Ultrafoam ${ }^{\mathrm{TM}}$ sponges) associated with gel of Matrigel $^{\mathrm{TM}}$ enhances the paracrine function of associated human MSCs, although the effect on IDO and on cell differentiation was not addressed. In 3D structures, MSCs are less fibrotic, secrete more cardiotrophic factors and retain anti-apoptotic and immunomodulatory functions. Among the secreted factors enhanced in the patch were BMP4, HGF, and VEGF, while the expression of PGDF remained unchanged. The expression of $\alpha$-SMA was decreased in 3D collagen as compared to 2D culture on collagen. In the collagen scaffold, MSCs maintain the level of pro-inflammatory cytokines such as IL6/IL8/Rantes, CXCL10/ IP-10 or antiinflammatory cytokines such as LIF, COX-2, TSG6, IDO (indolaleamine 2,3 dioxygnesase 1) and Il10. In 3D collagen scaffolds, the polarization of M2 macrophages seems to be reduced [47]. Recently, we have shown that IDO and MSC functionalities are enhanced in the 3D solid collagen scaffold compared to those obtained with 2D culture and, most importantly, our experiments were conducted without any tumor extract such as Matrigel ${ }^{\mathrm{TM}}$ [44]. This functionality is preserved following functionalization of the scaffold with RGD and also after differentiation of MSC towards contractile myofibroblasts. The RGD is known to improve cell survival by activating Ilk and Akt. We have also shown that the RGD on a preparation of human cardiospheres, containing some MSCs, decreases stress proteins [40]. Thus the use of collagen scaffolds functionalized with the RGD may improve cell survival.

\section{Conclusions}

Cardiac tissue is a complex 3D environment where the different cells, i.e. mainly cardiomyocytes, MSCs, fibroblasts, myofibroblasts and endothelial cells, interact in structural collagen type I and type III networks and matricilin proteins such as fibronectins and laminin. Integrins recognizing the RGD motif play a key role during cardiac development, pressure overload and after MI. Most cells interact with the environment through 3 types of integrin: collagen, laminin and RGD present on fibronectin or vitronectin) [52, 53, 72].

In collagen, in 2D or 3D environments, research has revealed very early spontaneous synthesis of laminin by cardiomyocytes for the organization of the contractile apparatus [36]. On collagen the RGD peptide is non-functional and the cardiomyocytes seeded in collagen scaffold witout functionalization with the RGD do not have all the signaling molecules necessary for their optimal differentiation. Thus, we propose functionalizing the collagen with the RGD peptide to provide additional signals [172]. We have demonstrated in a solid DHT collagen obtained by physical reticulation scaffold of low stiffness $1 \mathrm{kPa}$ [40] composed of 50\% 
type I and 50\% type III, highly porous collagen [40] obtained by physical reticulation by DHT scaffold how the modification with the RGD promote the differentiation of human MSCs or human cardiospheres towards a contractile phenotype while preserving their paracrine functionality. In the 3D scaffold, even after differentiation towards contractile myofibroblasts, the hMSC paracrine function is enhanced in relation to $2 \mathrm{D}$ cultures $[44,47]$. We have been able to develop a very efficient contractile tissue [38, 44-46] without the need for Matrigel ${ }^{\mathrm{TM}}$ or bioreactors, as previously reported in the same scaffold, but with Matrigel [31-33].

Gelatin is the heat-denaturized form of collagen containing the RGD peptide. Local stiffness, viscoelasticity [74, 75], microarchitecture [78] of undenatured collagen monomers or denaturized collagen (i.e. gelatin) is not the same $[50,53]$ and directly controls interaction with integrins [74, 75, 78]. For cardiac cells in general, drawing on RGD covalently bound to undenatured collagen is not the same as drawing on a RGD present on denatured collagen (i.e. gelatin) [41].

Functionalization of the natural non-denaturated collagen with the RGD peptide [38], could potentially improve most cardiac cell therapy where the classical undenaturated collagen is used. 


\title{
Figure legends.
}

\section{Figure 1. Different states of integrin activation, clustering, and focal adhesion maturation}

\author{
(Figure Adapted from B.H. Stumpf et al. Frontiers in Physiology, 2020) [184]
}

Integrins exist in 3 different conformations (i.e. Green Box). The classical form is the "bent closed" (BC) conformation that does not allow the binding of integrin extracellular domains to the extracellular peptide ligand present on the protein of the extracellular matrix (ECM). In BC, the intracytoplasmic $\alpha$ and $\beta$ tails are also very close and bound. The first step of integrin activation is an intracellular signal that will liberate the two tails from inhibitors. This will allow the binding of talin to the integrin $\beta$ intracellular tail. This in turn will provoke a small shift of the integrin extracellular domains (i.e. inside-out signal). This conformation will allow the ligation to the extracellular peptide ligand on the ECM protein such as RGD on a binding pocket that is formed by $\alpha$ and $\beta$ domains, but with a low affinity for the ligand (Extended closed). Ligand binding will directly induce a deformation of the intracellular $\beta$ chain. Contractility on the actin myosin, on the talin bound to the $\beta$ chain, will increase the distance between the two intracytoplasmic tails and provoke the modification of the extracellular domain with generation of integrins with high affinity for the ligand ("extended open").

Formation of the initial adhesion complex requires the integrin to be activated as well as clustered. The recruitment of the mechanical adaptor vinculin, which will bind to talin and actin after mechanical deformation by actin-myosin, will allow the formation of a highly effective mechanical bonds between cell cytoskeleton actin-myosin-talin- $\beta$ chain axe and the ECM. Clustering between integrins requires the ligand to be bound to the ECM, mechanical signals from outside and inside, high-density ligands, high stiffness of the ECM, and prolonged stimulation. During clustering, kindlin will bind the integrin $\beta$ chain together. Formation of FAK adhesion involves first the clustering between integrins $\alpha 5 \beta 1$, then the recruitment of $\alpha v \beta 3$ or $\alpha v \beta$ at the focal complex and other molecules to form adhesome. During clustering, integrin $\beta$ tails are physically linked by kindlin. In most mature focal adhesion complexes, the talin-vinculin will be replaced by direct fixation of tensin to $\beta$ tails.

\section{Figure 2. Expression of integrins on cardiomyocytes}

(Figure adapted from S. Israeli_Rosenberg et al. Circ. Res. 2014 and A.O. et al. Sessions Circ. Research 2016 ) [34]

Integrins are expressed in cardiomyocytes in 2 main locations: at the sarcomere level, between the different sarcomeres (at the level of the $\mathrm{Z}$ band), and at the level of the intercalated disc (intercardiomyocyte junctions). The main functions of intercalated discs are to transmit force between contractile cells and to ensure electrical coupling. Following integrin activation, there will be a physical link between the cardiac ECM integrins, the cell cytoskeleton, the sarcomeres and the nucleus. Intercellular stimulation by force at the level of the intercellular junction will provoke a physical link between the cytoskeleton and intercellular cadherin complexes by recruitment and will bind $\alpha$-catenin to $\beta$-catenin. The recruitment of vinculin will be associated with this complex and as for integrins will enhance resulting transmission forces. In the 
organization of the contractile apparatus, the main integrins involved is $\alpha 7 \beta 1$ integrins that recognize basal lamina laminin proteins locally secreted by cardiomyocytes. Sarcomere organization and development will also possibly depend on interactions with RGD peptides present on small fibronectin fragments also present at the basal lamina. While the cardiac extracellular matrix is mostly composed of collagen type I, in contact with cardiomyoccytes it is mostly the collagen type III. Beating and forces will maintain and reinforce all the levels of organization.

Figure 3. Integrin expression in fibroblasts and myofibroblasts and relationship with stress fibers and FAK adhesions

A. Organization of stress fibers in relation to integrin and FAK (Figure 3A adapted from M. Maninova et al. FEBS journal 2016)[185].

Tissue fibroblasts do not contain stress fibers. Mechanical stress will induce the formation of stress fibers. The organization of stress fibers is determined by the formation of adhesion contacts with extracellular matrix oligopeptides. Interaction with the RGD of fibronectin is essential for obtaining the most elaborate fibers. In fibroblasts and myofibroblasts, the actin fibers are organized in 4 levels: dorsal stress fibers, ventral stress fibers, arc stress fibers and perinuclear actin fibers. The presence of TGF $\beta$ collagen and fibronectin and extracellular mechanical forces will allow the transformation of protofibroblasts into myofibroblasts, with the incorporation of $\alpha$ SMA in ventral and arc stress fibers. The contraction of arc stress fibers will be transmitted through noncontractile dorsal stress fibers to reinforce adhesion sites.

B. Expression of integrins on fibroblasts and myofibroblasts (in red Boxes)

(Figure 3B adapted from Hinz B. et al. Experimental cell research 2019)[93].

Fibroblasts/Myofibroblats are able to recognize most extracellular matrix protein components: collagen (with integrins $\alpha 1 \beta 1, \alpha 2 \beta 1, \alpha 11 \beta 1, \alpha 1 \beta 2$ and $\alpha 2 \beta 2$ ), laminin (with $\alpha 1 \beta 3$ ), and RGD present in fibronectin (with $\alpha 5 \beta 1$ or $\alpha v \beta 3$ or $\alpha v \beta 5$ ) or RGD present in vitronectin (with $\alpha v \beta 1$, $\alpha v \beta 3, \alpha v \beta 6$ or $\alpha v \beta 8$ ). The capability of the myofibroblasts to interact with the RGD site of fibronectin is crucial for one of its main functions relating to the polymerization of the cellular fibronectin A matrix and secondary collagen incorporation. On more rigid substrates, the pull of myofibroblats on $\alpha v$ integrins ( $\alpha v \beta 1, \alpha v \beta 3, \alpha v \beta 6$ or $\alpha v \beta 8)$ on a RGD ligand present on the latent TGF $\beta$ allows the local release of TGF $\beta$. This is a major means of releasing TGF $\beta$ that is mainly stored and associated in active form in the ECM. Integrins on fibroblast/myofibroblats control the main functions such as migration, survival, apoptosis, differentiation and proliferation. The myofibroblasts are a major cellular mechanosensor of stiffness and viscoelasticity and are able to adapt to the stiffness of the microenvironment by controlling extracellular matrix degradation and synthesis. 
Author Contributions: O.S. decided on content and wrote the original draft of the manuscript. Y.L. collaborated in writing and revising the manuscript. P.F, J.C and M.A. revised the manuscript and approved the final version. All authors have read and agreed to the published version of the manuscript.

\section{Funding: None}

Conflicts of Interest: the authors declare no conflict of interest.

\section{References}

1 Wilmot KA, O'Flaherty M, Capewell S, Ford ES, Vaccarino V: Coronary Heart Disease Mortality Declines in the United States From 1979 Through 2011: Evidence for Stagnation in Young Adults, Especially Women. Circulation 2015;132:997-1002.

2 Bergmann O, Bhardwaj RD, Bernard S, Zdunek S, Barnabe-Heider F, Walsh S, Zupicich J, Alkass $\mathrm{K}$, Buchholz BA, Druid H, Jovinge S, Frisen J: Evidence for cardiomyocyte renewal in humans. Science 2009;324:98-102.

3 Frangogiannis NG: The extracellular matrix in myocardial injury, repair, and remodeling. J Clin Invest 2017;127:1600-1612.

4 Prabhu SD, Frangogiannis NG: The Biological Basis for Cardiac Repair After Myocardial Infarction: From Inflammation to Fibrosis. Circ Res 2016;119:91-112.

5 Ryan TD, Rothstein EC, Aban I, Tallaj JA, Husain A, Lucchesi PA, Dell'Italia L: Left ventricular eccentric remodeling and matrix loss are mediated by bradykinin and precede cardiomyocyte elongation in rats with volume overload. J Am Coll Cardiol 2007;49:811-821.

6 Bruggink AH, van Oosterhout MF, de Jonge N, Cleutjens JP, van Wichen DF, van Kuik J, Tilanus MG, Gmelig-Meyling FH, van den Tweel JG, de Weger RA: Type IV collagen degradation in the myocardial basement membrane after unloading of the failing heart by a left ventricular assist device. Lab Invest 2007;87:1125-1137.

7 Yanamandala M, Zhu W, Garry DJ, Kamp TJ, Hare JM, Jun HW, Yoon YS, Bursac N, Prabhu SD, Dorn GW, 2nd, Bolli R, Kitsis RN, Zhang J: Overcoming the Roadblocks to Cardiac Cell Therapy Using Tissue Engineering. J Am Coll Cardiol 2017;70:766-775.

8 Menasche P, Vanneaux V, Fabreguettes JR, Bel A, Tosca L, Garcia S, Bellamy V, Farouz Y, Pouly J, Damour O, Perier MC, Desnos M, Hagege A, Agbulut O, Bruneval P, Tachdjian G, Trouvin JH, Larghero $\mathrm{J}$ : Towards a clinical use of human embryonic stem cell-derived cardiac progenitors: a translational experience. Eur Heart J 2014;36:743-750.

$9 \quad$ Nguyen PK, Rhee JW, Wu JC: Adult Stem Cell Therapy and Heart Failure, 2000 to 2016: A Systematic Review. JAMA Cardiol 2016;1:831-841.

10 Blackburn NJ, Sofrenovic T, Kuraitis D, Ahmadi A, McNeill B, Deng C, Rayner KJ, Zhong Z, Ruel $M$, Suuronen EJ: Timing underpins the benefits associated with injectable collagen biomaterial therapy for the treatment of myocardial infarction. Biomaterials 2014;39:182-192.

11 Liu J, Narsinh KH, Lan F, Wang L, Nguyen PK, Hu S, Lee A, Han L, Gong Y, Huang M, Nag D, Rosenberg J, Chouldechova A, Robbins RC, Wu JC: Early stem cell engraftment predicts late cardiac functional recovery: preclinical insights from molecular imaging. Circ Cardiovasc Imaging 2012;5:481490.

12 Gao L, Gregorich ZR, Zhu W, Mattapally S, Oduk Y, Lou X, Kannappan R, Borovjagin AV, Walcott GP, Pollard AE, Fast VG, Hu X, Lloyd SG, Ge Y, Zhang J: Large Cardiac Muscle Patches Engineered From Human Induced-Pluripotent Stem Cell-Derived Cardiac Cells Improve Recovery From Myocardial Infarction in Swine. Circulation 2017;137:1712-1730. 
13 Pomeroy JE, Helfer A, Bursac N: Biomaterializing the promise of cardiac tissue engineering. Biotechnol Adv 2019;42:107353.

14 Jang $\mathrm{Y}$, Park $\mathrm{Y}$, Kim K: Engineering biomaterials to guide heart cells for matured cardiac tissue. J Coatings 2020;10:1-24.

15 Nguyen AH, Marsh P, Schmiess-Heine L, Burke PJ, Lee A, Lee J, Cao H: Cardiac tissue engineering: state-of-the-art methods and outlook. J Biol Eng 2019;13:57.

16 Zhang J, Zhu W, Radisic M, Vunjak-Novakovic G: Can We Engineer a Human Cardiac Patch for Therapy? Circ Res 2018;123:244-265.

17 Schussler O, Chachques JC, Mesana TG, Suuronen EJ, Lecarpentier Y, Ruel M: 3-dimensional structures to enhance cell therapy and engineer contractile tissue. Asian Cardiovasc Thorac Ann 2010;18:188-198.

18 Ye L, Chang YH, Xiong Q, Zhang P, Zhang L, Somasundaram P, Lepley M, Swingen C, Su L, Wendel JS, Guo J, Jang A, Rosenbush D, Greder L, Dutton JR, Zhang J, Kamp TJ, Kaufman DS, Ge Y: Cardiac repair in a porcine model of acute myocardial infarction with human induced pluripotent stem cell-derived cardiovascular cells. Cell Stem Cell 2014;15:750-761.

19 Ahmadi A, McNeill B, Vulesevic B, Kordos M, Mesana L, Thorn S, Renaud JM, Manthorp E, Kuraitis D, Toeg H, Mesana TG, Davis DR, Beanlands RS, DaSilva JN, deKemp RA, Ruel M, Suuronen EJ: The role of integrin alpha2 in cell and matrix therapy that improves perfusion, viability and function of infarcted myocardium. Biomaterials 2014;35:4749-4758.

20 Liu S, Jiang Z, Qiao L, Guo B, Xiao W, Zhang X, Chang L, Li Y: Integrin beta-3 is required for the attachment, retention and therapeutic benefits of human cardiospheres in myocardial infarction. $J$ Cell Mol Med 2017;22:382-389.

21 Higuchi T, Bengel FM, Seidl S, Watzlowik P, Kessler H, Hegenloh R, Reder S, Nekolla SG, Wester $\mathrm{HJ}$, Schwaiger M: Assessment of alphavbeta3 integrin expression after myocardial infarction by positron emission tomography. Cardiovasc Res 2008;78:395-403.

22 Sherif HM, Saraste A, Nekolla SG, Weidl E, Reder S, Tapfer A, Rudelius M, Higuchi T, Botnar RM, Wester HJ, Schwaiger M: Molecular imaging of early alphavbeta3 integrin expression predicts longterm left-ventricle remodeling after myocardial infarction in rats. J Nucl Med 2012;53:318-323.

23 Jenkins WS, Vesey AT, Stirrat C, Connell M, Lucatelli C, Neale A, Moles C, Vickers A, Fletcher A, Pawade T, Wilson I, Rudd JH, van Beek EJ, Mirsadraee S, Dweck MR, Newby DE: Cardiac alphaVbeta3 integrin expression following acute myocardial infarction in humans. Heart 2016;103:607-615.

24 van Wijk B, Gunst QD, Moorman AF, van den Hoff MJ: Cardiac regeneration from activated epicardium. PLoS One 2012;7:e44692.

25 Konstandin MH, Toko H, Gastelum GM, Quijada P, De La Torre A, Quintana M, Collins B, Din S, Avitabile D, Volkers M, Gude N, Fassler R, Sussman MA: Fibronectin is essential for reparative cardiac progenitor cell response after myocardial infarction. Circ Res 2013;113:115-125.

26 Wei K, Serpooshan V, Hurtado C, Diez-Cunado M, Zhao M, Maruyama S, Zhu W, Fajardo G, Noseda M, Nakamura K, Tian X, Liu Q, Wang A, Matsuura Y, Bushway P, Cai W, Savchenko A, Mahmoudi M, Schneider MD, van den Hoff MJ, Butte MJ, Yang PC, Walsh K, Zhou B, Bernstein D, Mercola M, RuizLozano P: Epicardial FSTL1 reconstitution regenerates the adult mammalian heart. Nature 2015;525:479-485.

27 Ladage D, Yaniz-Galende E, Rapti K, Ishikawa K, Tilemann L, Shapiro S, Takewa Y, MullerEhmsen J, Schwarz M, Garcia MJ, Sanz J, Hajjar RJ, Kawase Y: Stimulating myocardial regeneration with periostin Peptide in large mammals improves function post-myocardial infarction but increases myocardial fibrosis. PLoS One 2013;8:e59656.

28 Cortes-Morichetti M, Frati G, Schussler O, Duong Van Huyen JP, Lauret E, Genovese JA, Carpentier AF, Chachques JC: Association between a cell-seeded collagen matrix and cellular cardiomyoplasty for myocardial support and regeneration. Tissue Eng 2007;13:2681-2687.

29 Chachques JC, Trainini JC, Lago N, Cortes-Morichetti M, Schussler O, Carpentier A: Myocardial Assistance by Grafting a New Bioartificial Upgraded Myocardium (MAGNUM trial): clinical feasibility study. Ann Thorac Surg 2008;85:901-908. 
30 Chachques JC, Trainini JC, Lago N, Masoli OH, Barisani JL, Cortes-Morichetti M, Schussler O, Carpentier A: Myocardial assistance by grafting a new bioartificial upgraded myocardium (MAGNUM clinical trial): one year follow-up. Cell Transplant 2007;16:927-934.

31 Radisic M, Park H, Shing H, Consi T, Schoen FJ, Langer R, Freed LE, Vunjak-Novakovic G: Functional assembly of engineered myocardium by electrical stimulation of cardiac myocytes cultured on scaffolds. Proc Natl Acad Sci U S A 2004;101:18129-18134.

32 Radisic M, Malda J, Epping E, Geng W, Langer R, Vunjak-Novakovic G: Oxygen gradients correlate with cell density and cell viability in engineered cardiac tissue. Biotechnol Bioeng 2006;93:332-343.

33 Radisic M, Deen W, Langer R, Vunjak-Novakovic G: Mathematical model of oxygen distribution in engineered cardiac tissue with parallel channel array perfused with culture medium containing oxygen carriers. Am J Physiol Heart Circ Physiol 2005;288:H1278-1289.

34 Israeli-Rosenberg S, Manso AM, Okada H, Ross RS: Integrins and integrin-associated proteins in the cardiac myocyte. Circ Res 2014;114:572-586.

35 Bildyug N: Extracellular Matrix in Regulation of Contractile System in Cardiomyocytes. Int J Mol Sci 2019;20

36 Yang H, Borg TK, Liu H, Gao BZ: Interactive relationship between basement-membrane development and sarcomerogenesis in single cardiomyocytes. Exp Cell Res 2014;330:222-232.

37 Zhu J, Hoop CL, Case DA, Baum J: Cryptic binding sites become accessible through surface reconstruction of the type I collagen fibril. Sci Rep 2018;8:16646.

38 Schussler O, Coirault C, Louis-Tisserand M, Al-Chare W, Oliviero P, Menard C, Michelot R, Bochet P, Salomon DR, Chachques JC, Carpentier A, Lecarpentier Y: Use of arginine-glycine-aspartic acid adhesion peptides coupled with a new collagen scaffold to engineer a myocardium-like tissue graft. Nat Clin Pract Cardiovasc Med 2009;6:240-249.

39 Paez-Mayorga J, Hernandez-Vargas G, Ruiz-Esparza GU, Iqbal HMN, Wang X, Zhang YS, ParraSaldivar R, Khademhosseini A: Bioreactors for Cardiac Tissue Engineering. Adv Healthc Mater 2018;8:e1701504.

40 Chimenti I, Rizzitelli G, Gaetani R, Angelini F, lonta V, Forte E, Frati G, Schussler O, Barbetta A, Messina E, Dentini M, Giacomello A: Human cardiosphere-seeded gelatin and collagen scaffolds as cardiogenic engineered bioconstructs. Biomaterials 2011;32:9271-9281.

41 Grover CN, Cameron RE, Best SM: Investigating the morphological, mechanical and degradation properties of scaffolds comprising collagen, gelatin and elastin for use in soft tissue engineering. J Mech Behav Biomed Mater 2012;10:62-74.

42 Davidenko N, Schuster CF, Bax DV, Raynal N, Farndale RW, Best SM, Cameron RE: Control of crosslinking for tailoring collagen-based scaffolds stability and mechanics. Acta Biomater 2015;25:131142.

43 Malcor JD, Bax D, Hamaia SW, Davidenko N, Best SM, Cameron RE, Farndale RW, Bihan D: The synthesis and coupling of photoreactive collagen-based peptides to restore integrin reactivity to an inert substrate, chemically-crosslinked collagen. Biomaterials 2016;85:65-77.

44 Lecarpentier Y, Schussler O, Sakic A, Rincon-Garriz JM, Soulie P, Bochaton-Piallat ML, Kindler V: Human Bone Marrow Contains Mesenchymal Stromal Stem Cells That Differentiate In Vitro into Contractile Myofibroblasts Controlling T Lymphocyte Proliferation. Stem Cells Int 2018;2018:6134787. 45 Lecarpentier Y, Kindler V, Bochaton-Piallat ML, Sakic A, Claes V, Hebert JL, Vallee A, Schussler O: Tripeptide Arg-Gly-Asp (RGD) modifies the molecular mechanical properties of the non-muscle myosin IIA in human bone marrow-derived myofibroblasts seeded in a collagen scaffold. PLoS One 2019;14:e0222683.

46 Lecarpentier Y, Kindler V, Krokidis X, Bochaton-Piallat ML, Claes V, Hebert JL, Vallee A, Schussler O: Statistical Mechanics of Non-Muscle Myosin IIA in Human Bone Marrow-Derived Mesenchymal Stromal Cells Seeded in a Collagen Scaffold: A Thermodynamic Near-Equilibrium Linear System Modified by the Tripeptide Arg-Gly-Asp (RGD). Cells 2020;9

47 Rashedi I, Talele N, Wang XH, Hinz B, Radisic M, Keating A: Collagen scaffold enhances the regenerative properties of mesenchymal stromal cells. PLoS One 2017;12:e0187348. 
48 Dhavalikar P, Robinson A, Lan Z, Jenkins D, Chwatko M, Salhadar K, Jose A, Kar R, Shoga E, Kannapiran A, Cosgriff-Hernandez E: Review of Integrin-Targeting Biomaterials in Tissue Engineering. Adv Healthc Mater 2020:e2000795.

49 Lietha D, Izard T: Roles of Membrane Domains in Integrin-Mediated Cell Adhesion. Int J Mol Sci 2020;21

50 Zhao J, Santino F, Giacomini D, Gentilucci L: Integrin-Targeting Peptides for the Design of Functional Cell-Responsive Biomaterials. Biomedicines 2020;8

51 Paddillaya N, Mishra A, Kondaiah P, Pullarkat P, Menon GI, Gundiah N: Biophysics of CellSubstrate Interactions Under Shear. Front Cell Dev Biol 2019;7:251.

52 Bachmann M, Kukkurainen S, Hytonen VP, Wehrle-Haller B: Cell Adhesion by Integrins. Physiol Rev 2019;99:1655-1699.

53 Kechagia JZ, Ivaska J, Roca-Cusachs P: Integrins as biomechanical sensors of the microenvironment. Nat Rev Mol Cell Biol 2019;20:457-473.

54 Santoro R, Perrucci GL, Gowran A, Pompilio G: Unchain My Heart: Integrins at the Basis of iPSC Cardiomyocyte Differentiation. Stem Cells Int 2019;2019:8203950.

55 Sun Z, Costell M, Fassler R: Integrin activation by talin, kindlin and mechanical forces. Nat Cell Biol 2019;21:25-31.

56 Wolfenson H, Lavelin I, Geiger B: Dynamic regulation of the structure and functions of integrin adhesions. Dev Cell 2013;24:447-458.

57 Sun Z, Tseng HY, Tan S, Senger F, Kurzawa L, Dedden D, Mizuno N, Wasik AA, Thery M, Dunn $A R$, Fassler R: Kank2 activates talin, reduces force transduction across integrins and induces central adhesion formation. Nat Cell Biol 2016;18:941-953.

58 Oria R, Wiegand T, Escribano J, Elosegui-Artola A, Uriarte JJ, Moreno-Pulido C, Platzman I, Delcanale P, Albertazzi L, Navajas D, Trepat X, Garcia-Aznar JM, Cavalcanti-Adam EA, Roca-Cusachs P: Force loading explains spatial sensing of ligands by cells. Nature 2017;552:219-224.

59 Li J, Su Y, Xia W, Qin Y, Humphries MJ, Vestweber D, Cabanas C, Lu C, Springer TA: Conformational equilibria and intrinsic affinities define integrin activation. EMBO J 2017;36:629-645.

60 Sun Z, Guo SS, Fassler R: Integrin-mediated mechanotransduction. J Cell Biol 2016;215:445456.

61 Klapholz B, Brown NH: Talin - the master of integrin adhesions. J Cell Sci 2017;130:2435-2446.

62 Bays JL, DeMali KA: Vinculin in cell-cell and cell-matrix adhesions. Cell Mol Life Sci 2017;74:2999-3009.

63 Chopra A, Tabdanov E, Patel H, Janmey PA, Kresh JY: Cardiac myocyte remodeling mediated by N-cadherin-dependent mechanosensing. Am J Physiol Heart Circ Physiol 2011;300:H1252-1266.

64 Leckband DE, de Rooij J: Cadherin adhesion and mechanotransduction. Annu Rev Cell Dev Biol 2014;30:291-315.

65 Barry AK, Tabdili H, Muhamed I, Wu J, Shashikanth N, Gomez GA, Yap AS, Gottardi CJ, de Rooij J, Wang N, Leckband DE: alpha-catenin cytomechanics--role in cadherin-dependent adhesion and mechanotransduction. J Cell Sci 2014;127:1779-1791.

66 Yao M, Qiu W, Liu R, Efremov AK, Cong P, Seddiki R, Payre M, Lim CT, Ladoux B, Mege RM, Yan $\mathrm{J}$ : Force-dependent conformational switch of alpha-catenin controls vinculin binding. Nat Commun 2014;5:4525.

67 Pierschbacher MD, Ruoslahti E: Influence of stereochemistry of the sequence Arg-Gly-Asp-Xaa on binding specificity in cell adhesion. J Biol Chem 1987;262:17294-17298.

68 Taubenberger A, Cisneros DA, Friedrichs J, Puech PH, Muller DJ, Franz CM: Revealing early steps of alpha2beta1 integrin-mediated adhesion to collagen type I by using single-cell force spectroscopy. Mol Biol Cell 2007;18:1634-1644.

69 Changede R, Xu X, Margadant F, Sheetz MP: Nascent Integrin Adhesions Form on All Matrix Rigidities after Integrin Activation. Dev Cell 2015;35:614-621.

70 Grover CN, Gwynne JH, Pugh N, Hamaia S, Farndale RW, Best SM, Cameron RE: Crosslinking and composition influence the surface properties, mechanical stiffness and cell reactivity of collagenbased films. Acta Biomater 2012;8:3080-3090. 
71 Ricard-Blum S: The collagen family. Cold Spring Harb Perspect Biol 2011;3:1-19.

72 Kapp TG, Rechenmacher F, Neubauer S, Maltsev OV, Cavalcanti-Adam EA, Zarka R, Reuning U, Notni J, Wester HJ, Mas-Moruno C, Spatz J, Geiger B, Kessler H: A Comprehensive Evaluation of the Activity and Selectivity Profile of Ligands for RGD-binding Integrins. Sci Rep 2017;7:39805.

73 Roca-Cusachs P, Gauthier NC, Del Rio A, Sheetz MP: Clustering of alpha(5)beta(1) integrins determines adhesion strength whereas alpha(v)beta(3) and talin enable mechanotransduction. Proc Natl Acad Sci U S A 2009;106:16245-16250.

74 Darnell M, O'Neil A, Mao A, Gu L, Rubin LL, Mooney DJ: Material microenvironmental properties couple to induce distinct transcriptional programs in mammalian stem cells. Proc Natl Acad Sci U S A 2018;115:E8368-E8377.

75 Chaudhuri O, Cooper-White J, Janmey PA, Mooney DJ, Shenoy VB: Effects of extracellular matrix viscoelasticity on cellular behaviour. Nature 2020;584:535-546.

76 Sauer F, Oswald L, Ariza de Schellenberger A, Tzschatzsch H, Schrank F, Fischer T, Braun J, Mierke CT, Valiullin R, Sack I, Kas JA: Collagen networks determine viscoelastic properties of connective tissues yet do not hinder diffusion of the aqueous solvent. Soft Matter 2019;15:3055-3064.

77 Cameron AR, Frith JE, Cooper-White JJ: The influence of substrate creep on mesenchymal stem cell behaviour and phenotype. Biomaterials 2011;32:5979-5993.

78 Seo BR, Chen X, Ling L, Song YH, Shimpi AA, Choi S, Gonzalez J, Sapudom J, Wang K, Andresen Eguiluz RC, Gourdon D, Shenoy VB, Fischbach C: Collagen microarchitecture mechanically controls myofibroblast differentiation. Proc Natl Acad Sci U S A 2020;117:11387-11398.

79 Happe CL, Engler AJ: Mechanical Forces Reshape Differentiation Cues That Guide Cardiomyogenesis. Circ Res 2016;118:296-310.

80 Chiron S, Tomczak C, Duperray A, Laine J, Bonne G, Eder A, Hansen A, Eschenhagen T, Verdier C, Coirault C: Complex interactions between human myoblasts and the surrounding 3D fibrin-based matrix. PLoS One 2012; 7:e36173.

81 Saucerman JJ, Tan PM, Buchholz KS, McCulloch AD, Omens JH: Mechanical regulation of gene expression in cardiac myocytes and fibroblasts. Nat Rev Cardiol 2019;16:361-378.

82 Serrao GW, Turnbull IC, Ancukiewicz D, Kim DE, Kao E, Cashman TJ, Hadri L, Hajjar RJ, Costa KD: Myocyte-depleted engineered cardiac tissues support therapeutic potential of mesenchymal stem cells. Tissue Eng Part A 2012;18:1322-1333.

83 Talman V, Kivela R: Cardiomyocyte-Endothelial Cell Interactions in Cardiac Remodeling and Regeneration. Front Cardiovasc Med 2018;5:101.

84 Rother J, Richter C, Turco L, Knoch F, Mey I, Luther S, Janshoff A, Bodenschatz E, Tarantola M: Crosstalk of cardiomyocytes and fibroblasts in co-cultures. Open Biol 2015;5:150038.

85 Yang H, Cai C, Ye L, Rao Y, Wang Q, Hu D, Huang X: The relationship between angiotensinconverting enzyme gene insertion/deletion polymorphism and digestive cancer risk: Insights from a meta-analysis. J Renin Angiotensin Aldosterone Syst 2015;16:1306-1313.

86 Matsushita T, Oyamada M, Fujimoto K, Yasuda Y, Masuda S, Wada Y, Oka T, Takamatsu T: Remodeling of cell-cell and cell-extracellular matrix interactions at the border zone of rat myocardial infarcts. Circ Res 1999;85:1046-1055.

87 Sharp WW, Simpson DG, Borg TK, Samarel AM, Terracio L: Mechanical forces regulate focal adhesion and costamere assembly in cardiac myocytes. Am J Physiol 1997;273:H546-556.

88 Valencik ML, Zhang D, Punske B, Hu P, McDonald JA, Litwin SE: Integrin activation in the heart: a link between electrical and contractile dysfunction? Circ Res 2006;99:1403-1410.

89 Su Y, Tian H, Wei L, Fu G, Sun T: Integrin beta3 inhibits hypoxia-induced apoptosis in cardiomyocytes. Acta Biochim Biophys Sin (Shanghai) 2018;50:658-665.

90 van Putten S, Shafieyan Y, Hinz B: Mechanical control of cardiac myofibroblasts. J Mol Cell Cardiol 2015;93:133-142.

91 Schroer AK, Merryman WD: Mechanobiology of myofibroblast adhesion in fibrotic cardiac disease. J Cell Sci 2015;128:1865-1875.

92 Chen C, Li R, Ross RS, Manso AM: Integrins and integrin-related proteins in cardiac fibrosis. J Mol Cell Cardiol 2015;93:162-174. 
93 Hinz B, McCulloch CA, Coelho NM: Mechanical regulation of myofibroblast phenoconversion and collagen contraction. Exp Cell Res 2019;379:119-128.

94 Burnette DT, Shao L, Ott C, Pasapera AM, Fischer RS, Baird MA, Der Loughian C, Delanoe-Ayari H, Paszek MJ, Davidson MW, Betzig E, Lippincott-Schwartz J: A contractile and counterbalancing adhesion system controls the 3D shape of crawling cells. J Cell Biol 2014;205:83-96.

95 Beach JR, Bruun KS, Shao L, Li D, Swider Z, Remmert K, Zhang Y, Conti MA, Adelstein RS, Rusan NM, Betzig E, Hammer JA: Actin dynamics and competition for myosin monomer govern the sequential amplification of myosin filaments. Nat Cell Biol 2017;19:85-93.

96 Titus MA: Growing, splitting and stacking myosin II filaments. Nat Cell Biol 2017;19:77-79.

97 Hu S, Dasbiswas K, Guo Z, Tee YH, Thiagarajan V, Hersen P, Chew TL, Safran SA, Zaidel-Bar R, Bershadsky AD: Long-range self-organization of cytoskeletal myosin II filament stacks. Nat Cell Biol 2017;19:133-141.

98 Galdyszynska M, Bobrowska J, Lekka M, Radwanska P, Piera L, Szymanski J, Drobnik J: The stiffness-controlled release of interleukin- 6 by cardiac fibroblasts is dependent on integrin alpha2beta1. J Cell Mol Med 2020

99 Carracedo S, Lu N, Popova SN, Jonsson R, Eckes B, Gullberg D: The fibroblast integrin alpha11beta1 is induced in a mechanosensitive manner involving activin A and regulates myofibroblast differentiation. J Biol Chem 2010;285:10434-10445.

100 Sarrazy V, Koehler A, Chow ML, Zimina E, Li CX, Kato H, Caldarone CA, Hinz B: Integrins alphavbeta5 and alphavbeta3 promote latent TGF-beta1 activation by human cardiac fibroblast contraction. Cardiovasc Res 2014;102:407-417.

101 Margadant C, Sonnenberg A: Integrin-TGF-beta crosstalk in fibrosis, cancer and wound healing. EMBO Rep 2010;11:97-105.

102 Zhang Y, Li H, Wei R, Ma J, Zhao Y, Lian Z, Liu Z: Endothelial cells regulate cardiac myocyte reorganisation through beta1-integrin signalling. Cell Physiol Biochem 2015;35:1808-1820.

103 van der Flier A, Badu-Nkansah K, Whittaker CA, Crowley D, Bronson RT, Lacy-Hulbert A, Hynes RO: Endothelial alpha5 and alphav integrins cooperate in remodeling of the vasculature during development. Development 2010;137:2439-2449.

104 Xie L, Duncan MB, Pahler J, Sugimoto H, Martino M, Lively J, Mundel T, Soubasakos M, Rubin K, Takeda T, Inoue M, Lawler J, Hynes RO, Hanahan D, Kalluri R: Counterbalancing angiogenic regulatory factors control the rate of cancer progression and survival in a stage-specific manner. Proc Natl Acad Sci U S A 2011;108:9939-9944.

105 Kim S, Bell K, Mousa SA, Varner JA: Regulation of angiogenesis in vivo by ligation of integrin alpha5beta1 with the central cell-binding domain of fibronectin. Am J Pathol 2000;156:1345-1362.

106 Engler AJ, Sen S, Sweeney HL, Discher DE: Matrix elasticity directs stem cell lineage specification. Cell 2006;126:677-689.

107 Zwolanek D, Flicker M, Kirstatter E, Zaucke F, van Osch GJ, Erben RG: beta1 Integrins Mediate Attachment of Mesenchymal Stem Cells to Cartilage Lesions. Biores Open Access 2015;4:39-53.

108 Popov C, Radic T, Haasters F, Prall WC, Aszodi A, Gullberg D, Schieker M, Docheva D: Integrins alpha2beta1 and alpha11beta1 regulate the survival of mesenchymal stem cells on collagen I. Cell Death Dis 2011;2:e186.

109 Murray IR, Gonzalez ZN, Baily J, Dobie R, Wallace RJ, Mackinnon AC, Smith JR, Greenhalgh SN, Thompson Al, Conroy KP, Griggs DW, Ruminski PG, Gray GA, Singh M, Campbell MA, Kendall TJ, Dai J, Li Y, Iredale JP, Simpson H, Huard J, Peault B, Henderson NC: alphav integrins on mesenchymal cells regulate skeletal and cardiac muscle fibrosis. Nat Commun 2017;8:1118.

110 Jaukovic A, Abadjieva D, Trivanovic D, Stoyanova E, Kostadinova M, Pashova S, Kestendjieva S, Kukolj T, Jeseta M, Kistanova E, Mourdjeva M: Specificity of 3D MSC Spheroids Microenvironment: Impact on MSC Behavior and Properties. Stem Cell Rev Rep 2020;16:853-875.

111 van den Akker F, Deddens JC, Doevendans PA, Sluijter JP: Cardiac stem cell therapy to modulate inflammation upon myocardial infarction. Biochim Biophys Acta 2012;1830:2449-2458. 
112 Mangi AA, Noiseux N, Kong D, He H, Rezvani M, Ingwall JS, Dzau VJ: Mesenchymal stem cells modified with Akt prevent remodeling and restore performance of infarcted hearts. Nat Med 2003;9:1195-1201.

113 Li W, Ma N, Ong LL, Nesselmann C, Klopsch C, Ladilov Y, Furlani D, Piechaczek C, Moebius JM, Lutzow K, Lendlein A, Stamm C, Li RK, Steinhoff G: Bcl-2 engineered MSCs inhibited apoptosis and improved heart function. Stem Cells 2007;25:2118-2127.

114 Song SW, Chang W, Song BW, Song H, Lim S, Kim HJ, Cha MJ, Choi E, Im SH, Chang BC, Chung $\mathrm{N}$, Jang $\mathrm{Y}$, Hwang KC: Integrin-linked kinase is required in hypoxic mesenchymal stem cells for strengthening cell adhesion to ischemic myocardium. Stem Cells 2009;27:1358-1365.

115 Cho YH, Cha MJ, Song BW, Kim IK, Song H, Chang W, Lim S, Ham O, Lee SY, Choi E, Kwon HM, Hwang KC: Enhancement of MSC adhesion and therapeutic efficiency in ischemic heart using lentivirus delivery with periostin. Biomaterials 2011;33:1376-1385.

116 Salinas CN, Anseth KS: The influence of the RGD peptide motif and its contextual presentation in PEG gels on human mesenchymal stem cell viability. J Tissue Eng Regen Med 2008;2:296-304.

117 Simpson DL, Dudley SC, Jr.: Modulation of human mesenchymal stem cell function in a threedimensional matrix promotes attenuation of adverse remodelling after myocardial infarction. J Tissue Eng Regen Med 2011;7:192-202.

118 Maureira P, Marie PY, Yu F, Poussier S, Liu Y, Groubatch F, Falanga A, Tran N: Repairing chronic myocardial infarction with autologous mesenchymal stem cells engineered tissue in rat promotes angiogenesis and limits ventricular remodeling. J Biomed Sci 2012;19:93.

119 Di Spigna G, lannone M, Ladogana P, Salzano S, Ventre M, Covelli B, De Marinis E, Postiglione L: Human cardiac multipotent adult stem cells in 3D matrix: new approach of tissue engineering in cardiac regeneration post-infarction. J Biol Regul Homeost Agents 2017;31:911-921.

120 Li TS, Cheng K, Lee ST, Matsushita S, Davis D, Malliaras K, Zhang Y, Matsushita N, Smith RR, Marban E: Cardiospheres recapitulate a niche-like microenvironment rich in stemness and cell-matrix interactions, rationalizing their enhanced functional potency for myocardial repair. Stem Cells 2010;28:2088-2098.

121 Li X, Tamama K, Xie X, Guan J: Improving Cell Engraftment in Cardiac Stem Cell Therapy. Stem Cells Int 2016;2016:7168797.

122 van Laake LW, van Donselaar EG, Monshouwer-Kloots J, Schreurs C, Passier R, Humbel BM, Doevendans PA, Sonnenberg A, Verkleij AJ, Mummery CL: Extracellular matrix formation after transplantation of human embryonic stem cell-derived cardiomyocytes. Cell Mol Life Sci 2010;67:277290.

123 Burgess ML, Terracio L, Hirozane T, Borg TK: Differential integrin expression by cardiac fibroblasts from hypertensive and exercise-trained rat hearts. Cardiovasc Pathol 2002;11:78-87.

124 Cheng P, Andersen P, Hassel D, Kaynak BL, Limphong P, Juergensen L, Kwon C, Srivastava D: Fibronectin mediates mesendodermal cell fate decisions. Development 2013;140:2587-2596.

125 Gaetani R, Yin C, Srikumar N, Braden R, Doevendans PA, Sluijter JP, Christman KL: CardiacDerived Extracellular Matrix Enhances Cardiogenic Properties of Human Cardiac Progenitor Cells. Cell Transplant 2015;25:1653-1663.

126 Hanna A, Frangogiannis NG: The Role of the TGF-beta Superfamily in Myocardial Infarction. Front Cardiovasc Med 2019;6:140.

127 Sun M, Opavsky MA, Stewart DJ, Rabinovitch M, Dawood F, Wen WH, Liu PP: Temporal response and localization of integrins beta1 and beta3 in the heart after myocardial infarction: regulation by cytokines. Circulation 2003;107:1046-1052.

128 Bouvet M, Claude O, Roux M, Skelly D, Masurkar N, Mougenot N, Nadaud S, Blanc C, Delacroix C, Chardonnet S, Pionneau C, Perret C, Yaniz-Galende E, Rosenthal N, Tregouet DA, Marazzi G, Silvestre JS, Sassoon D, Hulot JS: Anti-integrin alphav therapy improves cardiac fibrosis after myocardial infarction by blunting cardiac PW1(+) stromal cells. Sci Rep 2020;10:11404.

129 Gaetani R, Zizzi EA, Deriu MA, Morbiducci U, Pesce M, Messina E: When Stiffness Matters: Mechanosensing in Heart Development and Disease. Front Cell Dev Biol 2020;8:334. 
130 Carson D, Hnilova M, Yang X, Nemeth CL, Tsui JH, Smith AS, Jiao A, Regnier M, Murry CE, Tamerler C, Kim DH: Nanotopography-Induced Structural Anisotropy and Sarcomere Development in Human Cardiomyocytes Derived from Induced Pluripotent Stem Cells. ACS Appl Mater Interfaces 2016;8:21923-21932.

131 Nicolas J, Magli S, Rabbachin L, Sampaolesi S, Nicotra F, Russo L: 3D Extracellular Matrix Mimics: Fundamental Concepts and Role of Materials Chemistry to Influence Stem Cell Fate. Biomacromolecules 2020;21:1968-1994.

132 Jang $\mathrm{Y}$, Park $\mathrm{Y}, \mathrm{Kim} \mathrm{J}$ : engineering biomaterials to guide herat cells for mature cardiac tissue. coatings 2020;10:1-24.

133 Tallawi M, Rosellini E, Barbani N, Cascone MG, Rai R, Saint-Pierre G, Boccaccini AR: Strategies for the chemical and biological functionalization of scaffolds for cardiac tissue engineering: a review. J R Soc Interface 2015;12:20150254.

134 Spicer CD, Pashuck ET, Stevens MM: Achieving Controlled Biomolecule-Biomaterial Conjugation. Chem Rev 2018;118:7702-7743.

135 Engelmayr GC, Jr., Cheng M, Bettinger CJ, Borenstein JT, Langer R, Freed LE: Accordion-like honeycombs for tissue engineering of cardiac anisotropy. Nat Mater 2008;7:1003-1010.

136 Wang Z, Lee SJ, Cheng HJ, Yoo JJ, Atala A: 3D bioprinted functional and contractile cardiac tissue constructs. Acta Biomater 2018;70:48-56.

137 Liu J, Miller K, Ma X, Dewan S, Lawrence N, Whang G, Chung P, McCulloch AD, Chen S: Direct 3D bioprinting of cardiac micro-tissues mimicking native myocardium. Biomaterials 2020;256:120204.

138 Sasaki D, Matsuura K, Seta H, Haraguchi Y, Okano T, Shimizu T: Contractile force measurement of human induced pluripotent stem cell-derived cardiac cell sheet-tissue. PLoS One 2018;13:e0198026. 139 Davidenko N, Schuster CF, Bax DV, Farndale RW, Hamaia S, Best SM, Cameron RE: Evaluation of cell binding to collagen and gelatin: a study of the effect of 2D and 3D architecture and surface chemistry. J Mater Sci Mater Med 2016;27:148.

140 Hirt MN, Hansen A, Eschenhagen T: Cardiac tissue engineering: state of the art. Circ Res 2014;114:354-367.

141 Park H, Radisic M, Lim JO, Chang BH, Vunjak-Novakovic G: A novel composite scaffold for cardiac tissue engineering. In Vitro Cell Dev Biol Anim 2005;41:188-196.

142 Davis ME, Motion JP, Narmoneva DA, Takahashi T, Hakuno D, Kamm RD, Zhang S, Lee RT: Injectable self-assembling peptide nanofibers create intramyocardial microenvironments for endothelial cells. Circulation 2005;111:442-450.

143 Eschenhagen T, Eder A, Vollert I, Hansen A: Physiological aspects of cardiac tissue engineering. Am J Physiol Heart Circ Physiol 2012;303:H133-143.

144 Shadrin IY, Allen BW, Qian Y, Jackman CP, Carlson AL, Juhas ME, Bursac N: Cardiopatch platform enables maturation and scale-up of human pluripotent stem cell-derived engineered heart tissues. Nat Commun 2017;8:1825.

145 Ronaldson-Bouchard K, Ma SP, Yeager K, Chen T, Song L, Sirabella D, Morikawa K, Teles D, Yazawa M, Vunjak-Novakovic G: Advanced maturation of human cardiac tissue grown from pluripotent stem cells. Nature 2018;556:239-243.

146 Riegler J, Tiburcy M, Ebert A, Tzatzalos E, Raaz U, Abilez OJ, Shen Q, Kooreman NG, Neofytou E, Chen VC, Wang M, Meyer T, Tsao PS, Connolly AJ, Couture LA, Gold JD, Zimmermann WH, Wu JC: Human Engineered Heart Muscles Engraft and Survive Long Term in a Rodent Myocardial Infarction Model. Circ Res 2015;117:720-730.

147 Tiburcy M, Hudson JE, Balfanz P, Schlick S, Meyer T, Chang Liao ML, Levent E, Raad F, Zeidler S, Wingender E, Riegler J, Wang M, Gold JD, Kehat I, Wettwer E, Ravens U, Dierickx P, van Laake LW, Goumans MJ, Khadjeh S, Toischer K, Hasenfuss G, Couture LA, Unger A, Linke WA, Araki T, Neel B, Keller G, Gepstein L, Wu JC, Zimmermann WH: Defined Engineered Human Myocardium With Advanced Maturation for Applications in Heart Failure Modeling and Repair. Circulation 2017;135:1832-1847.

148 Chong JJ, Yang X, Don CW, Minami E, Liu YW, Weyers JJ, Mahoney WM, Van Biber B, Cook SM, Palpant NJ, Gantz JA, Fugate JA, Muskheli V, Gough GM, Vogel KW, Astley CA, Hotchkiss CE, Baldessari 
A, Pabon L, Reinecke H, Gill EA, Nelson V, Kiem HP, Laflamme MA, Murry CE: Human embryonic-stemcell-derived cardiomyocytes regenerate non-human primate hearts. Nature 2014;510:273-277.

149 Ruvinov E, Cohen S: Alginate biomaterial for the treatment of myocardial infarction: Progress, translational strategies, and clinical outlook: From ocean algae to patient bedside. Adv Drug Deliv Rev 2015;96:54-76.

150 Sapir Y, Kryukov O, Cohen S: Integration of multiple cell-matrix interactions into alginate scaffolds for promoting cardiac tissue regeneration. Biomaterials 2010;32:1838-1847.

151 Shachar M, Tsur-Gang O, Dvir T, Leor J, Cohen S: The effect of immobilized RGD peptide in alginate scaffolds on cardiac tissue engineering. Acta Biomater 2010;7:152-162.

152 Zhang D, Shadrin IY, Lam J, Xian HQ, Snodgrass HR, Bursac N: Tissue-engineered cardiac patch for advanced functional maturation of human ESC-derived cardiomyocytes. Biomaterials 2013;34:5813-5820.

153 Naito H, Melnychenko I, Didie M, Schneiderbanger K, Schubert P, Rosenkranz S, Eschenhagen $\mathrm{T}$, Zimmermann WH: Optimizing engineered heart tissue for therapeutic applications as surrogate heart muscle. Circulation 2006;114:172-78.

154 Jackman C, Li H, Bursac N: Long-term contractile activity and thyroid hormone supplementation produce engineered rat myocardium with adult-like structure and function. Acta Biomater 2018;78:98-110.

155 Hirt MN, Boeddinghaus J, Mitchell A, Schaaf S, Bornchen C, Muller C, Schulz H, Hubner N, Stenzig J, Stoehr A, Neuber C, Eder A, Luther PK, Hansen A, Eschenhagen T: Functional improvement and maturation of rat and human engineered heart tissue by chronic electrical stimulation. $\mathrm{J}$ Mol Cell Cardiol 2014;74:151-161.

156 Jackman CP, Shadrin IY, Carlson AL, Bursac N: Human Cardiac Tissue Engineering: From Pluripotent Stem Cells to Heart Repair. Curr Opin Chem Eng 2015;7:57-64.

157 Radisic M, Fast VG, Sharifov OF, lyer RK, Park H, Vunjak-Novakovic G: Optical mapping of impulse propagation in engineered cardiac tissue. Tissue Eng Part A 2009;15:851-860.

158 Park H, Bhalla R, Saigal R, Radisic M, Watson N, Langer R, Vunjak-Novakovic G: Effects of electrical stimulation in C2C12 muscle constructs. J Tissue Eng Regen Med 2008;2:279-287.

159 Dawson J, Schussler O, Al-Madhoun A, Menard C, Ruel M, Skerjanc IS: Collagen scaffolds with or without the addition of RGD peptides support cardiomyogenesis after aggregation of mouse embryonic stem cells. In Vitro Cell Dev Biol Anim 2011;47:653-664.

160 Miyagi Y, Chiu LL, Cimini M, Weisel RD, Radisic M, Li RK: Biodegradable collagen patch with covalently immobilized VEGF for myocardial repair. Biomaterials 2010;32:1280-1290.

161 Hall ML, Ogle BM: Cardiac Extracellular Matrix Modification as a Therapeutic Approach. Adv Exp Med Biol 2018;1098:131-150.

162 Taylor DA, Sampaio LC, Ferdous Z, Gobin AS, Taite LJ: Decellularized matrices in regenerative medicine. Acta Biomater 2018;74:74-89.

163 Fong $\mathrm{AH}$, Romero-Lopez M, Heylman CM, Keating M, Tran D, Sobrino A, Tran AQ, Pham $H H$, Fimbres C, Gershon PD, Botvinick EL, George SC, Hughes CC: Three-Dimensional Adult Cardiac Extracellular Matrix Promotes Maturation of Human Induced Pluripotent Stem Cell-Derived Cardiomyocytes. Tissue Eng Part A 2016;22:1016-1025.

164 Guyette JP, Charest JM, Mills RW, Jank BJ, Moser PT, Gilpin SE, Gershlak JR, Okamoto T, Gonzalez G, Milan DJ, Gaudette GR, Ott HC: Bioengineering Human Myocardium on Native Extracellular Matrix. Circ Res 2015;118:56-72.

165 Asgari M, Latifi N, Heris HK, Vali H, Mongeau L: In vitro fibrillogenesis of tropocollagen type III in collagen type I affects its relative fibrillar topology and mechanics. Sci Rep 2017;7:1392.

166 Hein S, Schaper J: The extracellular matrix in normal and diseased myocardium. J Nucl Cardiol 2001;8:188-196.

167 Telemeco TA, Ayres C, Bowlin GL, Wnek GE, Boland ED, Cohen N, Baumgarten CM, Mathews J, Simpson DG: Regulation of cellular infiltration into tissue engineering scaffolds composed of submicron diameter fibrils produced by electrospinning. Acta Biomater 2005;1:377-385. 
168 Bil'diug NB, ludintseva NM, Pinaev GP: [Contractile apparatus organization of cardiomyocytes upon their cultivation in collagen gels]. Tsitologiia 2015;56:822-827.

169 Bil'diug NB, Pinaev GP: [Extracellular matrix dependence of the cardiomyocyte contractile apparatus organization]. Tsitologiia 2013;55:713-724.

170 Zhang W, Kong CW, Tong MH, Chooi WH, Huang N, Li RA, Chan BP: Maturation of human embryonic stem cell-derived cardiomyocytes (hESC-CMs) in 3D collagen matrix: Effects of niche cell supplementation and mechanical stimulation. Acta Biomater 2016;49:204-217.

171 Pieper JS, Oosterhof A, Dijkstra PJ, Veerkamp JH, van Kuppevelt TH: Preparation and characterization of porous crosslinked collagenous matrices containing bioavailable chondroitin sulphate. Biomaterials 1999;20:847-858.

172 Hersel U, Dahmen C, Kessler H: RGD modified polymers: biomaterials for stimulated cell adhesion and beyond. Biomaterials 2003;24:4385-4415.

173 Tsur-Gang O, Ruvinov E, Landa N, Holbova R, Feinberg MS, Leor J, Cohen S: The effects of peptide-based modification of alginate on left ventricular remodeling and function after myocardial infarction. Biomaterials 2009;30:189-195.

174 Kamata S, Miyagawa S, Fukushima S, Nakatani S, Kawamoto A, Saito A, Harada A, Shimizu T, Daimon T, Okano T, Asahara T, Sawa Y: Improvement of cardiac stem cell sheet therapy for chronic ischemic injury by adding endothelial progenitor cell transplantation: analysis of layer-specific regional cardiac function. Cell Transplant 2013;23:1305-1319.

175 Cao F, Sadrzadeh Rafie AH, Abilez OJ, Wang H, Blundo JT, Pruitt B, Zarins C, Wu JC: In vivo imaging and evaluation of different biomatrices for improvement of stem cell survival. J Tissue Eng Regen Med 2007;1:465-468.

176 Freeman BT, Kouris NA, Ogle BM: Tracking fusion of human mesenchymal stem cells after transplantation to the heart. Stem Cells Transl Med 2015;4:685-694.

177 Kutschka I, Chen IY, Kofidis T, Arai T, von Degenfeld G, Sheikh AY, Hendry SL, Pearl J, Hoyt G, Sista R, Yang PC, Blau HM, Gambhir SS, Robbins RC: Collagen matrices enhance survival of transplanted cardiomyoblasts and contribute to functional improvement of ischemic rat hearts. Circulation 2006;114:I167-173.

178 Tongers J, Webber MJ, Vaughan EE, Sleep E, Renault MA, Roncalli JG, Klyachko E, Thorne T, Yu Y, Marquardt KT, Kamide CE, Ito A, Misener S, Millay M, Liu T, Jujo K, Qin G, Losordo DW, Stupp SI, Kishore R: Enhanced potency of cell-based therapy for ischemic tissue repair using an injectable bioactive epitope presenting nanofiber support matrix. J Mol Cell Cardiol 2014;74:231-239.

179 Callegari A, Bollini S, Iop L, Chiavegato A, Torregrossa G, Pozzobon M, Gerosa G, De Coppi P, Elvassore N, Sartore S: Neovascularization induced by porous collagen scaffold implanted on intact and cryoinjured rat hearts. Biomaterials 2007;28:5449-5461.

180 Gaballa MA, Sunkomat JN, Thai H, Morkin E, Ewy G, Goldman S: Grafting an acellular 3dimensional collagen scaffold onto a non-transmural infarcted myocardium induces neo-angiogenesis and reduces cardiac remodeling. J Heart Lung Transplant 2006;25:946-954.

181 Xiang Z, Liao R, Kelly MS, Spector M: Collagen-GAG scaffolds grafted onto myocardial infarcts in a rat model: a delivery vehicle for mesenchymal stem cells. Tissue Eng 2006;12:2467-2478.

182 Shimazaki M, Nakamura K, Kii I, Kashima T, Amizuka N, Li M, Saito M, Fukuda K, Nishiyama T, Kitajima S, Saga Y, Fukayama M, Sata M, Kudo A: Periostin is essential for cardiac healing after acute myocardial infarction. J Exp Med 2008;205:295-303.

183 Chiu LL, Weisel RD, Li RK, Radisic M: Defining conditions for covalent immobilization of angiogenic growth factors onto scaffolds for tissue engineering. J Tissue Eng Regen Med 2010;5:69-84. 184 Henning Stumpf B, Ambriovic-Ristov A, Radenovic A, Smith AS: Recent Advances and Prospects in the Research of Nascent Adhesions. Front Physiol 2020;11:574371.

185 Maninova M, Vomastek T: Dorsal stress fibers, transverse actin arcs, and perinuclear actin fibers form an interconnected network that induces nuclear movement in polarizing fibroblasts. FEBS J 2016;283:3676-3693. 